Article

\title{
Magnetic nanoplatforms for in situ modification of macromolecules: synthesis, characterization and photoinactivating power of cationic nanoiman-porphyrin conjugates
}

Ana Coral Scanone, Natalia Soledad Gsponer, Maria Gabriela Alvarez, Daniel Alejandro Heredia, Andrés M. Durantini, and Edgardo Néstor Durantini

ACS Appl. Bio Mater., Just Accepted Manuscript • DOI: 10.1021/acsabm.0c00625 • Publication Date (Web): 06 Aug 2020

Downloaded from pubs.acs.org on August 8, 2020

\section{Just Accepted}

"Just Accepted" manuscripts have been peer-reviewed and accepted for publication. They are posted online prior to technical editing, formatting for publication and author proofing. The American Chemical Society provides "Just Accepted" as a service to the research community to expedite the dissemination of scientific material as soon as possible after acceptance. "Just Accepted" manuscripts appear in full in PDF format accompanied by an HTML abstract. "Just Accepted" manuscripts have been fully peer reviewed, but should not be considered the official version of record. They are citable by the Digital Object Identifier (DOI®). "Just Accepted" is an optional service offered to authors. Therefore, the "Just Accepted" Web site may not include all articles that will be published in the journal. After a manuscript is technically edited and formatted, it will be removed from the "Just Accepted" Web site and published as an ASAP article. Note that technical editing may introduce minor changes to the manuscript text and/or graphics which could affect content, and all legal disclaimers and ethical guidelines that apply to the journal pertain. ACS cannot be held responsible for errors or consequences arising from the use of information contained in these "Just Accepted" manuscripts. 
Magnetic nanoplatforms for in situ modification of macromolecules: synthesis, characterization and photoinactivating power of cationic nanoiman-porphyrin conjugates

\author{
Ana C. Scanone, Natalia S. Gsponer, María G. Alvarez, Daniel A. Heredia, Andrés M. Durantini and \\ Edgardo N. Durantini* \\ IDAS-CONICET, Departamento de Química, Facultad de Ciencias Exactas, Físico-Químicas y \\ Naturales, Universidad Nacional de Río Cuarto, Ruta Nacional 36 Km 601, X5804BYA Río Cuarto, \\ Córdoba, Argentina.
}

\footnotetext{
${ }^{*}$ Corresponding author.
}

E-mail address: edurantini@exa.unrc.edu.ar (E.N. Durantini) 


\begin{abstract}
Nanoplatform concept was developed to synthesized accessible photoactive magnetic nanoparticles (MNPs) of $\mathrm{Fe}_{3} \mathrm{O}_{4}$ coated with silica. This approach was based on the covalent binding of 5,10,15,20-tetrakis(pentafluorophenyl)porphyrin $\left(\mathrm{TPPF}_{20}\right)$ to aminopropyl-grafted MNPs by nucleophilic aromatic substitution reaction $\left(\mathrm{S}_{\mathrm{N}} \mathrm{Ar}\right)$ to obtain conjugate MNP-P1. After in situ modification, the remaining pentafluorophenyl groups of $\mathrm{TPPF}_{20}$ attached to $\mathrm{MNPs}$ were substituted by dimethylaminoethoxy groups to form MNP-P2. The basic amine group of these conjugates can be protonated in aqueous media. In addition, MNP-P1 and MNP-P2 were intrinsically charged to produce cationic conjugates $\mathrm{MNP}^{+}-\mathrm{P} 1$ and $\mathrm{MNP}^{+}-\mathrm{P}^{+}$by methylation. All of them were easily purified by magnetic decantation in high yields. The average size of the MNPs was $\sim 15 \mathrm{~nm}$ and the main difference between these conjugates was the greater coating with positive charges of $\mathrm{MNP}^{+}-$ $\mathrm{P} 2^{+}$, as showed by the zeta potential values. Absorption spectra exhibited the Soret and Q bands characteristic of $\mathrm{TPPF}_{20}$ linked to MNPs. Furthermore, these conjugates showed red fluorescence emission of porphyrin with quantum yields of $0.011-0.036$. The photodynamic effect sensitized by the conjugates indicated the efficient formation of singlet molecular oxygen in different media, reaching quantum yields values of $0.17-0.34$ in $N, N$-dimethylformamide. The photodynamic activity of the conjugates was evaluated to inactivate the Gram-positive bacteria Staphylococcus aureus, the Gram-negative bacteria Escherichia coli and the yeast Candida albicans. The modified cationic $\mathrm{MNP}^{+}-\mathrm{P} 2^{+}$was the most effective conjugate for photodynamic inactivation (PDI) of microorganisms. Binding of this conjugate to bacteria and photoinactivation capability was checked by means of fluorescence microscopy. Also, sustainable use by recycling was determined after three PDI treatments. Therefore, this methodology is a suitable scaffold for the in situ modification of conjugates and in particular, $\mathrm{MNP}^{+}-\mathrm{P} 2^{+}$represents a useful photodynamic active material to eradicate microorganisms.
\end{abstract}


KEYWORD: magnetic nanoparticles, porphyrin, nanoplatform, photodynamic inactivation, antimicrobial. 


\section{INTRODUCTION}

Magnetic nanoparticles (MNPs) are suitable to be decorated with different functional group and due to its magnetic properties, they can be visualized and guided in water and organic solvents by means of an external magnetic field. ${ }^{1}$ This effect allowed to exploit different pathways and applications of MNPs, from cellular targeting and hyperthermia therapy to the petroleum industry for emulsion separations..$^{2-4}$ In particular, an interesting potential use of photosensitizer conjugated to MNPs involve the photodynamic inactivation (PDI) of microorganisms. ${ }^{5,6}$ This procedure is based on the addition of a photosensitizer to the medium contaminated with pathogenic microorganisms. Next, irradiation with visible light mainly leads to the formation of reactive oxygen species (ROS), which cause lethal damage to the microbial cells. ${ }^{7}$ In this sense, nanomagnet-porphyrin hybrids have been studied as efficient photosensitizers to inactivate bacteria and phages ${ }^{8,9}$ Also, porphyrin conjugated to MNPs has been proposed to control microbial proliferation by PDI. ${ }^{10}$

Many of these MNPs-conjugated photosensitizers were formed using $\mathrm{AB}_{3}$-porphyrins. These asymmetrically substituted tetrapyrrole macrocycles contain three identical molecular structures B and one different $\mathrm{A}$ at the meso-position. In those cases, the structure $\mathrm{A}$ bears a functional group that can be used to link the porphyrin with other molecules, while B contain substituents that allow changing the polarity and interaction with the media. ${ }^{11}$ These porphyrins can be synthesized by a binary mixed aldehyde and pyrrole condensation. The purification requires slow chromatographic separation with very poor yields $(<3 \%){ }^{12}$ Also, $\mathrm{AB}_{3}$-porphyrins can be obtained by the condensation of a dipyrromethane with a binary mixture of aldehydes. This approach involves two steps of synthesis and purification, using flash chromatography a large amount of organic solvents, with yields $<15 \%{ }^{11,13}$ However, there are no reports that indicate the use of MNPs as nanoplatform for the in situ modification of photosensitizers. Therefore, a porphyrin with a sophisticated synthetic procedure and low reaction yield could be easily modified starting from a tetrapyrrole macrocycle covalently linked to MNPs. After each synthetic step, a desired macrocycle attached to MNPs can be isolated from 
byproducts by washing using the magnetic decantation technique. This purification method also avoids the use of excessive amounts of organic solvents that are usually required in organic synthesis.

Considering our interest in developing accessible photoactive MNPs to inactivate microorganisms, here we report this new nanoplatform concept to facilitate the synthesis of four conjugates using 5,10,15,20-tetrakis(pentafluorophenyl)porphyrin $\left(\mathrm{TPPF}_{20}\right)$ as a structurally modifiable photosensitizer. This $\mathrm{A}_{4}$-porphyrin is commercially accessible or can be easily synthesized with good yields. ${ }^{14,15}$ This porphyrin is a suitable and versatile building block for the construction of meso-substituted tetrapyrrolic macrocycles through the nucleophilic aromatic substitution reaction $\left(\mathrm{S}_{\mathrm{N}} \mathrm{Ar}\right) .{ }^{16}$ After in situ modification different conjugates were obtained, two of them (MNP-P1 and MNP-P2) do not present net intrinsic charges, while the other two $\left(\mathrm{MNP}^{+}-\mathrm{P} 1\right.$ and $\mathrm{MNP}^{+}-\mathrm{P} 2^{+}$) are substituted with cationic groups (Figure 1). The absorption and fluorescent spectroscopic characteristics of the MNPs-conjugated porphyrins were assessed in different media. Moreover, their photodynamic properties were studied in the presence of different photooxidizable substrates. The photodynamic activity of the conjugates was investigated to inactivate the Grampositive bacteria Staphylococcus aureus, the Gram-negative bacteria Escherichia coli and the yeast Candida albicans. These bacteria are representative of microorganisms responsible for numerous hospital-acquired infections and water-related diseases. ${ }^{17,18}$ Furthermore, invasive fungal infections are a major cause of morbidity and mortality in hospitalized patients. ${ }^{19}$ Therefore, this study was also focused on the ability to applicate these MNPs-conjugated porphyrins to photoinactivate these pathogens.

\section{EXPERIMENTAL SECTION}

\subsection{Synthesis of MNPs and conjugates}

The conjugates of MNPs with $\mathrm{TPPF}_{20}$ were synthesized following the procedures schematically shown in Figure S1. TPPF 20 was synthesized as previously reported. ${ }^{15}$ 


\subsubsection{Synthesis of $\mathrm{MNPSiNH}_{2}$}

The synthesis of $\mathrm{MNPSiNH}_{2}$ was done as previously described. ${ }^{10,20}$ Briefly, MNPs of iron oxide $\left(\mathrm{Fe}_{3} \mathrm{O}_{4}\right)$ were synthesized from $\mathrm{FeCl}_{2}$ and $\mathrm{FeCl}_{3}$ using the coprecipitation technique, followed by treatment with sodium metasilicate $\left(\mathrm{Na}_{2} \mathrm{SiO}_{3}\right)$ to obtain MNPs coated with silica (MNPSi, average size $10 \pm 2 \mathrm{~nm}$ ). Finally, (3-aminopropyl)triethoxysilane (APTS) was added to form MNPs functionalized with amine groups ( $\mathrm{MNPSiNH}_{2}$, average size $11 \pm 2 \mathrm{~nm}$ ).

\subsubsection{Synthesis of MNP-P1}

The covalent binding of $\mathrm{TPPF}_{20}$ to $\mathrm{MNPSiNH}_{2}$ was performed as described for pentafluorophenyl derivatives with amine groups with same modifications. ${ }^{21,22}$ From a suspension of $\mathrm{MNPSiNH}_{2}$ in water $\left(84 \mathrm{~mL}, 4 \mathrm{mg} \mathrm{MNPSiNH}_{2} / \mathrm{mL}\right)$ the solvent was eliminated by magnetic decantation. Then, the $\mathrm{MNPSiNH}_{2}$ were washed with freshly distilled $N, N$-dimethylformamide (DMF) and resuspended in $10 \mathrm{~mL}$ of the same solvent. This suspension was mixed with a solution of $\mathrm{TPPF}_{20}(2 \mathrm{~mL}, 20 \mathrm{mM})$ in DMF. The reaction mixture was stirred at room temperature for $48 \mathrm{~h}$. The progress of the reaction was followed by TLC analysis (silica gel; $n$-hexane / chloroform 3:2) of the supernatant in the mixture, which showed the consumption of $\operatorname{TPPF}_{20}\left(\mathrm{R}_{\mathrm{f}}=0.45\right)$ due to the formation of the conjugate with the MNPs. The reaction mixture was sonicated for $5 \mathrm{~min}$, then placed on a neodymium magnet for $5 \mathrm{~min}$ to produce magnetic decantation of the MNPs. The supernatant was discarded to remove non-magnetic materials. MNPs were resuspended in $10 \mathrm{~mL} \mathrm{DMF}$, sonicated for $5 \mathrm{~min}$, kept for $15 \mathrm{~min}$ at room temperature, recollected by magnetic decantation and the solvent was discarded. This washing process was repeated several times until the presence of impurities were not detected in the supernatant by UV-visible absorption spectroscopy in the range of $250-800 \mathrm{~nm}$. This first washing process was followed by a similar procedure but using acetone and methanol. In each washing step, $10 \mathrm{~mL}$ of solvent were used. The amount of $\mathrm{TPPF}_{20}$ attached to the MNPs was calculated by subtracting the amount of recovered $\mathrm{TPPF}_{20}$ in the combined washing solvents 
(measured by UV-visible absorption spectroscopy) to the initial amount of TPPF 20 used. The MNPP1 conjugate obtained was resuspended in $84 \mathrm{~mL}$ water.

\subsubsection{Synthesis of $\mathrm{MNP}^{+}-\mathrm{P1}$ and $\mathrm{MNPSiN}^{+}\left(\mathrm{CH}_{3}\right)_{3}$}

The formation of cationic groups was carried out with a large excess of $\mathrm{CH}_{3} \mathrm{I} .{ }^{8}$ The water in the MNP-P1 suspension ( $21 \mathrm{~mL}, 4 \mathrm{mg}$ MNP-P1/mL) was discarded by magnetic decantation. After successive washing with DMF, the MNPs were resuspended in $21 \mathrm{~mL}$ of the same solvent and $2 \mathrm{~mL}$ of $\mathrm{CH}_{3} \mathrm{I}$ were added. The reaction mixture was stirred $72 \mathrm{~h}$ at $40{ }^{\circ} \mathrm{C}$. After this reaction time, the new $\mathrm{MNP}^{+}-\mathrm{P} 1$ were washed with DMF by magnetic decantation as described in 2.1.2 and resuspended in $21 \mathrm{~mL}$ water. The same procedure was used to obtain $\operatorname{MNPSiN}^{+}\left(\mathrm{CH}_{3}\right)_{3}$.

\subsubsection{Synthesis of MNP-P2}

The derivatization of $\mathrm{TPPF}_{20}$ attached to MNP-P1 was achieved similarly to the reactions of pentafluorophenyl porphyrinoids with alcohols. ${ }^{23}$ After washing MNP-P1 (42 mL, $4 \mathrm{mg}$ MNP$\mathrm{P} 1 / \mathrm{mL}$ ) by magnetic decantation with freshly distilled tetrahydrofuran (THF), the conjugate was resuspended in THF $(10 \mathrm{~mL})$. Then, 2-(N,N-dimethylamino)ethanol (DAE, $80 \mu \mathrm{mol})$, anhydrous potassium hydroxide $(\mathrm{KOH}, 64 \mu \mathrm{mol})$ and tetrabutylammonium bromide $(\mathrm{TBAB}, 100 \mu \mathrm{L})$ were added. The reaction mixture was continuosly stirred at room temperature for $12 \mathrm{~h}$. The MNP-P2 were purified whashing with THF and water by magnetic decantation following the methodology detailed in 2.1.2 and the conjugated was resuspended in $42 \mathrm{~mL}$ water.

\subsubsection{Synthesis of $\mathrm{MNP}^{+}-\mathrm{P2}^{+}$}

An aliquot of MNP-P2 $(21 \mathrm{~mL})$ was methylated with $\mathrm{CH}_{3} \mathrm{I}$ following the procedure described above for the synthesis of $\mathrm{MNP}^{+}-\mathrm{P} 1$. After washing with DMF by magnetic decantation as indicated in 2.1.2, $\mathrm{MNP}^{+}-\mathrm{P} 2^{+}$was resuspended in $21 \mathrm{~mL}$ water. 


\subsection{Preparation of samples of the MNPs conjugates}

After the synthesis of each conjugate, aliquots that were used as a stock suspension in the different studies were separated (Figure S1). The recovery of the conjugates after each process was calculated by weighing. Stock solutions were prepared at the same concentration for all conjugates, which was $4 \mathrm{mg} \mathrm{MNPs/mL} \mathrm{containing} 10 \mathrm{nmol}$ porphyrin/mg MNPs. Before each experiment, the solutions were sonicated for $5 \mathrm{~min}$ to disaggregate the MNPs.

\subsection{Morphology of MNPs and zeta potential determinations}

The morphology and size of the MNPs were examined by transmission electron microscopy (TEM). A drop of each suspension of MNPs conjugate was placed on a formvar-coated copper grid and the solvent was evaporated under reduced pressure. The zeta potential $(\zeta)$ determinations were performed using aqueous dispersions of the different MNPs conjugates. The measurements were carried out in $1 \mathrm{mg} / \mathrm{mL}$ dispersions of the corresponding samples, ultrasonically dispersed for $5 \mathrm{~min}$. Electrophoretic mobilities were converted to $\zeta$ using the Smoluchowski equation. ${ }^{24}$

\subsection{Spectroscopic studies}

UV-visible absorption and fluorescence spectra of the different conjugates (concentration between 1-2 $\mu \mathrm{M}$ in immobilized porphyrin) were recorded as reported. ${ }^{20}$ An excitation wavelength of $428 \mathrm{~nm}$ was used to acquire the emission spectra. 5,10,15,20-Tetrakis(4sulfonatophenyl)porphyrin (TPPS $\left.{ }^{4-}\right)$ was used as a reference $\left(\Phi_{\mathrm{F}}=0.080\right)$ to determine the fluorescence quantum yield $\left(\Phi_{\mathrm{F}}\right)$ of each MNPs conjugates in water. ${ }^{25}$ All spectral measurements were performed at room temperature using a quartz cell of $1 \mathrm{~cm}$ path length. The absorbances of the conjugates and TPPS $^{4-}(<0.05)$ were matched at the excitation wavelength. The areas under the emission spectra were integrated and compared in the $600-800 \mathrm{~nm}$ range.

\subsection{Steady state photolysis of substrates}


Photooxidation of tetrasodium 2,2'-(anthracene-9,10-diyl)bis(methylmalonate) (ABMM) and 9,10-dimethylantracene (DMA) were performed in aqueous media and DMF, respectivaly. ${ }^{10,20}$ Samples of anthracene derivative $(35 \mu \mathrm{M})$ in the presence of MNPs conjugates ( $3 \mu \mathrm{M}$ of immobilized porphyrin) were irradiated with light $(455-800 \mathrm{~nm})$ in $1 \mathrm{~cm}$ path length quartz cells $(2 \mathrm{~mL})$. The photooxidation rate of both substrates were studied by following the decrease of the absorbance at $378 \mathrm{~nm}$ for DMA and $379 \mathrm{~nm}$ for ABMM. The observed rate constants $\left(k_{\mathrm{obs}}\right)$ and quantum yields of $\mathrm{O}_{2}\left({ }^{1} \Delta_{\mathrm{g}}\right)$ production $\left(\Phi_{\Delta}\right)$ were calculated as previously reported, using TPPS $^{4-}$ was used as a reference $\left(\Phi_{\Delta}=0.71\right) .26,27$

\subsection{Strains and cultures of microorganism}

The microbial strains were $S$. aureus ATCC 25923, E. coli EC7 and C. albicans PC31 that were previously characterized and identified. ${ }^{28}$ Cultivation of microorganisms and handling of cells to obtain $\sim 10^{8}$ colony forming units $(\mathrm{CFU}) / \mathrm{mL}$ for bacteria and $\sim 10^{6} \mathrm{CFU} / \mathrm{mL}$ for yeast in phosphatebuffered saline (PBS, $\mathrm{pH}=7.4$ ) were achieved as reported. ${ }^{10}$ Viable microbial cells were quantified after serial dilutions 10 -fold in PBS by the spread plate technique after an incubation of $24 \mathrm{~h}$ for bacteria or $48 \mathrm{~h}$ for yeast at $37^{\circ} \mathrm{C}$ in the dark.

\subsection{Photoinactivation of microorganisms}

Cell suspensions $(1.9 \mathrm{~mL})$ of E. coli $\left(10^{8} \mathrm{CFU} / \mathrm{mL}\right)$ and $S$. aureus $\left(10^{8} \mathrm{CFU} / \mathrm{mL}\right)$ and $C$. albicans $\left(10^{6} \mathrm{CFU} / \mathrm{mL}\right)$ in PBS were incubated with $0.1 \mathrm{~mL}$ MNPs conjugate in Pyrex culture tubes $(13 \times 100 \mathrm{~mm})$ for $30 \mathrm{~min}$ in the dark at $37^{\circ} \mathrm{C}$. That mean the addition of $0.4 \mathrm{mg}$ MNPs conjugate in a final volume of $2 \mathrm{~mL}\left(0.2 \mathrm{mg}\right.$ MNPs conjugate $/ \mathrm{mL}, 2 \mu \mathrm{M}$ immobilized $\left.\mathrm{TPPF}_{20}\right)$. The same conditions were used with $\mathrm{MNPSiN}^{+}\left(\mathrm{CH}_{3}\right)_{3}$. Subsequently, $200 \mu \mathrm{L}$ of the cell suspensions were transferred to 96 -well microtiter plates. The cultures were exposed to visible light $\left(90 \mathrm{~mW} / \mathrm{cm}^{2}\right)$ for different irradiation periods $(5,15$ and $30 \mathrm{~min}$, which match the light fluences of 27, 81 and 162 $\mathrm{J} / \mathrm{cm}^{2}$, respectively). Description of the light source was previously reported. ${ }^{29}$ After each irradiation 
time, a $100 \mu$ aliquot of wells was taken to perform 10-fold serial dilutions in PBS of the bacterial cells. Different wells were used for each irradiation period. Viable cells were quantified as mentioned in section 2.6. Three values were obtained per each condition and each experiment was repeated separately three times. For recycling experiments, MNPs conjugates were recovered by magnetic decantation after PDI treatment and resuspended in a new cell suspension. An average time of 5 min was used to collect the MNP by the application of the external magnetic field. The cultures were kept in the dark for $30 \mathrm{~min}$ and irradiated again to complete the cycle. ${ }^{10}$ The unpaired $t$-test was used to obtain the significance of differences between experiments. Differences between means were tested for significance by one-way ANOVA. Results were statistically significant with a confidence level of $95 \%(p<0.05)$. Data were denoted as the mean \pm standard deviation of each experiment. Controls were performed with cultures of microorganisms in the dark, with and without conjugates and irradiated cells in the absence of conjugates.

\subsection{Bioimaging and PDI by fluorescence microscopy}

Fluorescence microscopy investigations were carried out using the methodology previously reported with same modifications..$^{20,30}$ Bacterial suspension $(100 \mu \mathrm{L})$ was incubated in a chamber composed of a polymeric cylinder glue to a coverslip for $30 \mathrm{~min}$. This procedure was used to allow cells to attach to the glass surface. Unbound bacteria were removed by washing with PBS. Bioimaging experiments were performed addicting $200 \mu \mathrm{L} \mathrm{MNP}^{+}-\mathrm{P} 2^{+}(0.8 \mathrm{mg} \mathrm{MNPs})$ to attached cells on glass surface of a chamber. Cells were incubated for $30 \mathrm{~min}$ in dark, the chamber was rinsed to eliminate MNPs the chamber was rinsed with PBS to remove the MNPs that were not bound to the cells and filled with $500 \mu \mathrm{L}$ PBS. After PDI treatments, the cell viability was determined with propidium iodide (PI). Fluorescence images PI were performed using an emission band pass filter (645/75). The fluorescence emitted from the $\mathrm{MNP}^{+}-\mathrm{P} 2^{+}$or PI was collected by the same objective and captured in a CMOS camera. Phase contrast images were also attained to verify bacterial presence in the sample chamber. 


\section{RESULTS AND DISCUSSION}

\subsection{Design of the new conjugates nanomagnet-porphyrin}

The synthesis of MNPs conjugates with $\mathrm{TPPF}_{20}$ are summarized in Figure 1. This is an idealized representation of the conjugates in their simplest forms. Possibly, some of the $\mathrm{TPPF}_{20}$ porphyrins may be attached to the MNPs by more than one pentafluorophenyl group. The formation of the nanoplatforms $\left(\mathrm{MNPSiNH}_{2}\right)$ was done following the procedure described in a previous work. ${ }^{10}$ Subsequently, $\mathrm{TPPF}_{20}$ was selected as a porphyrin derivative with good versatility that allows the modifications of its functional groups with simple synthetic procedures. With a $\mathrm{A}_{4}$ symmetry, this porphyrin is decorated with four pentafluorophenyl group. The synthetic versatility relies on the fluorine atom at the para position, which is prone to undergo $\mathrm{S}_{\mathrm{N}} \mathrm{Ar}$ by different nucleofiles. ${ }^{22,31}$ The reaction of pentafluorophenyl substituents in the porphyrin macrocycle to the amine groups of MNPs was previously described. ${ }^{8,9}$ To synthesize MNP-P1, $\mathrm{MNPSiNH}_{2}$ was mixed with an excess of $\mathrm{TPPF}_{20}$. The coupling reaction was done in DMF stirring for $48 \mathrm{~h}$ at room temperature. MNP-P1 is a versatile nanoplatform that was used as starting material to obtain the other three conjugates. First, the porphyrin structure in this conjugate was modified to obtain MNP-P2. For a successful reaction, the following stoichiometric ratio was necessary (with respect to the concentration of $\mathrm{TPPF}_{20}$ in MNP-P1): $\mathrm{TPPF}_{20} 1$ equiv., DAE 20 equiv. and $\mathrm{KOH} 16$ equiv. Due to $\mathrm{TPPF}_{20}$ bound to MNP has three substitutable groups, the previous stoichiometric triplicates. For this purpose, MNP-P1 was reacted with DAE in basic conditions using TBAB as a catalyst. After $12 \mathrm{~h}$ at room temperature the photosensitizing nanomagnet containing dimethylaminoethoxy ramifications was obtained (MNPP2). This modification provides to each porphyrin unit of basic amine groups, which can acquire positive charges by protonation in a biological medium. ${ }^{28,32}$ These ramifications can improve the MNPs binding to the microbial cell wall. It is known that the great majority of pathogens have an overall negative charge on the external wall. ${ }^{7}$ With this under consideration, cationic analogues of MNP-P1 and MNP-P2 were synthesized. In the case of MNP-P1, the primary amine groups attached 
to the MNPs were exhaustively methylated with an excess of methyl iodide to obtain $\mathrm{MNP}^{+}-\mathrm{P} 1$. Similarly, primary and tertiary amines in MNP-P2 were precursors of positive charges to form $\mathrm{MNP}^{+}-$ $\mathrm{P} 2^{+}$. Through this reaction both, the free aminopropyl groups on the core of the $\mathrm{Fe}_{3} \mathrm{O}_{4} \mathrm{MNPs}$ and the dimethylaminoethoxy substituents attached to the porphyrin were positively charged. Thus, both conjugates are surrounded by intrinsic positive charges. In particular, in the $\mathrm{MNP}^{+}-\mathrm{P} 2^{+}$the cationic centers are isolated from the porphyrin ring by an aliphatic spacer, which provides a higher mobility of the charge facilitating the interaction with the cell envelope. To remark on these synthetic pathways based on a nanoplatform concept is that in all cases the conjugates were easily purified by magnetic decantation and the MNPs were recovered in $>95 \%$ yields.

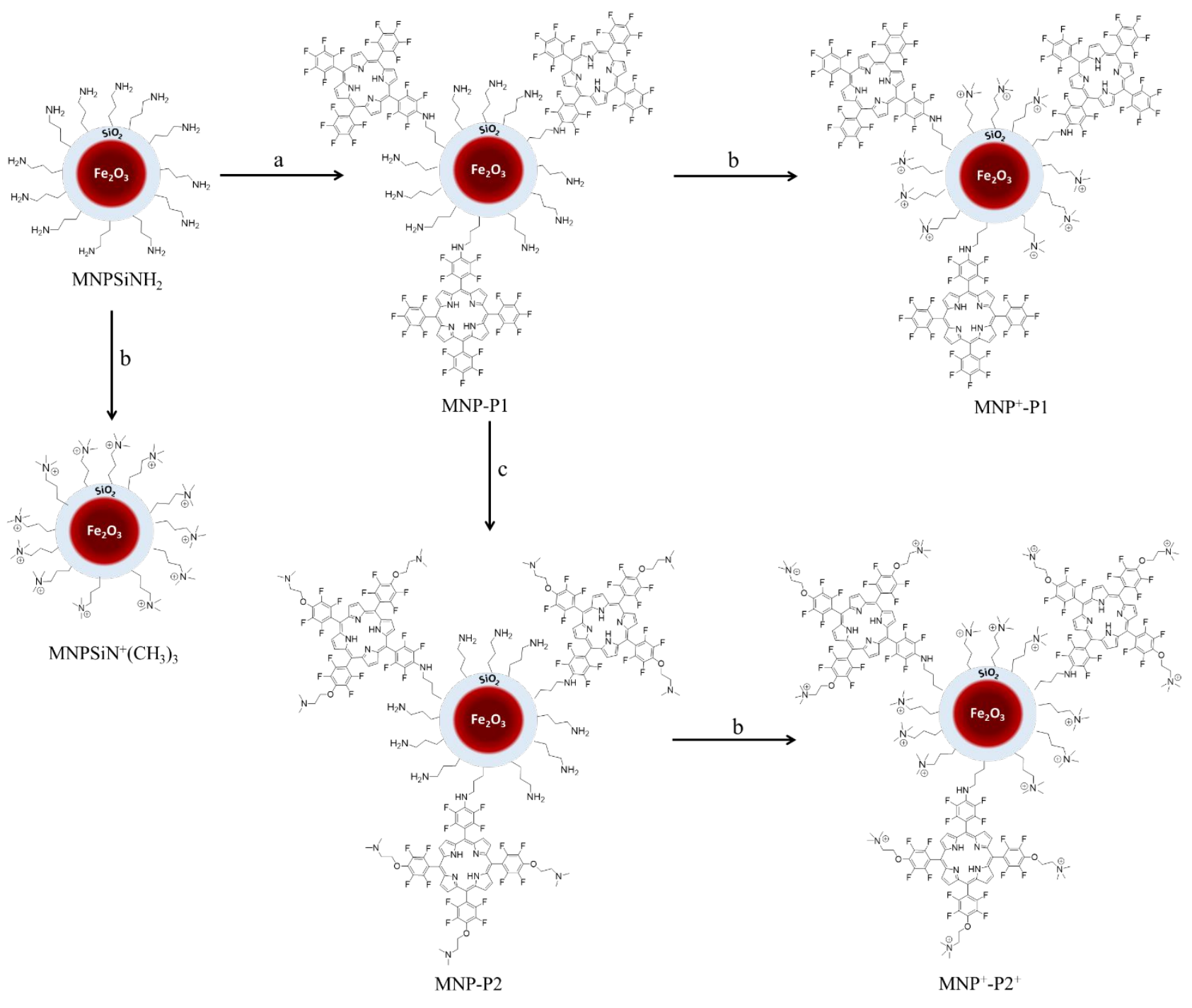


Figure 1. Simplified structures of the MNPs synthesized in this work. Reagents and conditions: a) $\mathrm{TPPF}_{20}$, DMF, r.t., 48 h; b) $\mathrm{CH}_{3} \mathrm{I}, \mathrm{DMF}, 40^{\circ} \mathrm{C}, 72$ h; c) DAE, THF, KOH, TBAB, r.t., 12 h.

\subsection{Characterization of conjugates by TEM and zeta potential}

TEM images reveled that the average size of the MNPs in all conjugates was $12 \pm 2 \mathrm{~nm}$ (Figure S2). Particles with similar sizes were previously obtained using a similar synthetic procedure. ${ }^{10}$ The coating of the MNPs with $\mathrm{TPPF}_{20}$ does not change the size of the particles. The images showed the formation of aggregates between MNPs due to the magnetization and attraction between the nanomagnet. Similar behavior was previously found for porphyrins attached to MNPs. ${ }^{8,20}$

On the other hand, the zeta potential $(\zeta)$ was determined to evaluate the surface load and stability of the suspensions. The values of $\zeta$ are indicated in Table 1 . The $\zeta$ measurements yielded positive values in all conjugates. There is not a significant difference on the $\zeta$ values between the two control MNPSiNH $\mathrm{MNPSiN}^{+}\left(\mathrm{CH}_{3}\right)_{3}$ as expected due to protonation of the amine at $\mathrm{pH} \sim 7$. However, the $\zeta$ value dropped from $28 \mathrm{mV}$ to $16 \mathrm{mV}$ and from 25 to $19 \mathrm{mV}$ upon covalently binding $\mathrm{TPPF}_{20}$ to $\mathrm{MNPSiNH}_{2}$ and $\mathrm{MNPSiN}{ }^{+}\left(\mathrm{CH}_{3}\right)_{3}$, respectively. The difference in these values may be due to the fact that the bulky neutral porphyrin groups on the external layer of the MNPs produce a decrease in the overall surface charge, decreasing the amount of exposed cationic amines. However, $\zeta$ values increased $11 \mathrm{mV}$ and $14 \mathrm{mV}$ upon decorating MNP-P1 and $\mathrm{MNP}^{+}-\mathrm{P} 1$ with tertiary amines to yield MNP-P2 and $\mathrm{MNP}^{+}-\mathrm{P} 2^{+}$, respectively. These increase in $\zeta$ values with the amount of positive charges is expected for this kind of aggregates, as it was previously described. ${ }^{33,34}$ An overall analysis of the colloidal stability and in accordance to the electrostatic interactions of the conjugates, the order is the following: $\mathrm{MNP}^{+}-\mathrm{P} 2^{+}>\mathrm{MNP}-\mathrm{P} 2>\mathrm{MNP}^{+}-\mathrm{P} 1 \sim \mathrm{MNP}-\mathrm{P} 1$. An increasing on the amount of positive charges enhances MNPs repulsion and favors the stability.

\subsection{Absorption and fluorescence spectroscopic properties of conjugates}


The UV-visible absorption spectra of MNPs conjugates are shown in Figure 2A. Furthermore, they are compared with those of MNPSiNH2 and a water-soluble porphyrin TPPS ${ }^{4-}$, which was used as a reference. Spectra of MNPs conjugates were corrected considering the scattering of the $\mathrm{MNPSiNH}_{2}$ (Figure 2A, inset). Suspensions of these conjugates in water showed the typical porphyrin Soret band at $\sim 430 \mathrm{~nm}$ (Table 1). Also, the four Q-bands can be observed between 515 and $650 \mathrm{~nm}$ of the modified $\mathrm{TPPF}_{20}$ attached to the MNPs. Therefore, absorption spectra also confirmed the binding of $\mathrm{TPPF}_{20}$ to MNPs. Moreover, the absorption spectra of conjugates were carried out in DMF (Figure S3). Similar to those obtained in water, well defined bands of porphyrin are observed in this organic solvent and thus, they can be compared with that of TPPF 20 . Upon attachment of TPPF 20 and its consecutive analogues to the MNPs, a $\sim 20 \mathrm{~nm}$ bathochromic shift in the Soret band was observed in all the conjugates. This displacement of the band to higher wavelength can be attributed to immobilization of the porphyrin core to the MNPs with different electronic properties. This effect was also visualized in similar systems when a porphyrin is anchored to MNPs. ${ }^{10,35}$

The fluorescence emission spectra of the conjugates and TPPS ${ }^{4-}$ in water are given in Figure 2B. Porphyrin unit attached to MNPs presented two bands in the four conjugates centered at 657 and $713 \mathrm{~nm}$, which are characteristic of free-base porphyrin derivatives (Table 1). These emission bands correspond to $\mathrm{Qx}(0-0)$ and $\mathrm{Qx}(0-1)$ transitions. ${ }^{11,36}$ The spectrum of porphyrin bound to MNPs in water maintains the shape of $\mathrm{TPPF}_{20}$ in $\mathrm{DMF}$, with the band at higher wavelength more intense than the first. ${ }^{36}$ The presence of the MNPs was also reflected on a $20 \mathrm{~nm}$ shift to lower energy compare to $\mathrm{TPPF}_{20}$ alone in DMF. Furthermore, a Stokes shifts of $\sim 5 \mathrm{~nm}$ were calculated for the conjugates taken into account the intersection of the absorption and fluorescence spectra of the $\mathrm{Qx}(0-0)$ band in water. This small Stokes shifts indicate that in this porphyrin the spectroscopic energies are similar to the relaxed energies of the lowest singlet excited state, according to the rigid planar structure of the tetrapyrrolic macrocycle. Therefore, only a minor geometric relaxation occurs in the first excited state of $\mathrm{TPPF}_{20}$ attached to MNPs. Fluorescence quantum yields $\left(\Phi_{\mathrm{F}}\right)$ of these conjugates were calculated in water using TPPS4- as a reference (Table 1). The values of $\Phi_{\mathrm{F}}$ for conjugates are smaller than that 
of a free-base porphyrin in aqueous medium or $\mathrm{TPPF}_{20}$ in DMF. ${ }^{36}$ As it was previously shown, MNPs can quench emission from the singlet excited state of photosensitizers due to oxidative photoinduced electron transfer (PeT) from the porphyrin singlet excited state to the $\mathrm{Fe}_{3} \mathrm{O}_{4}$ nucleus. ${ }^{20,37}$
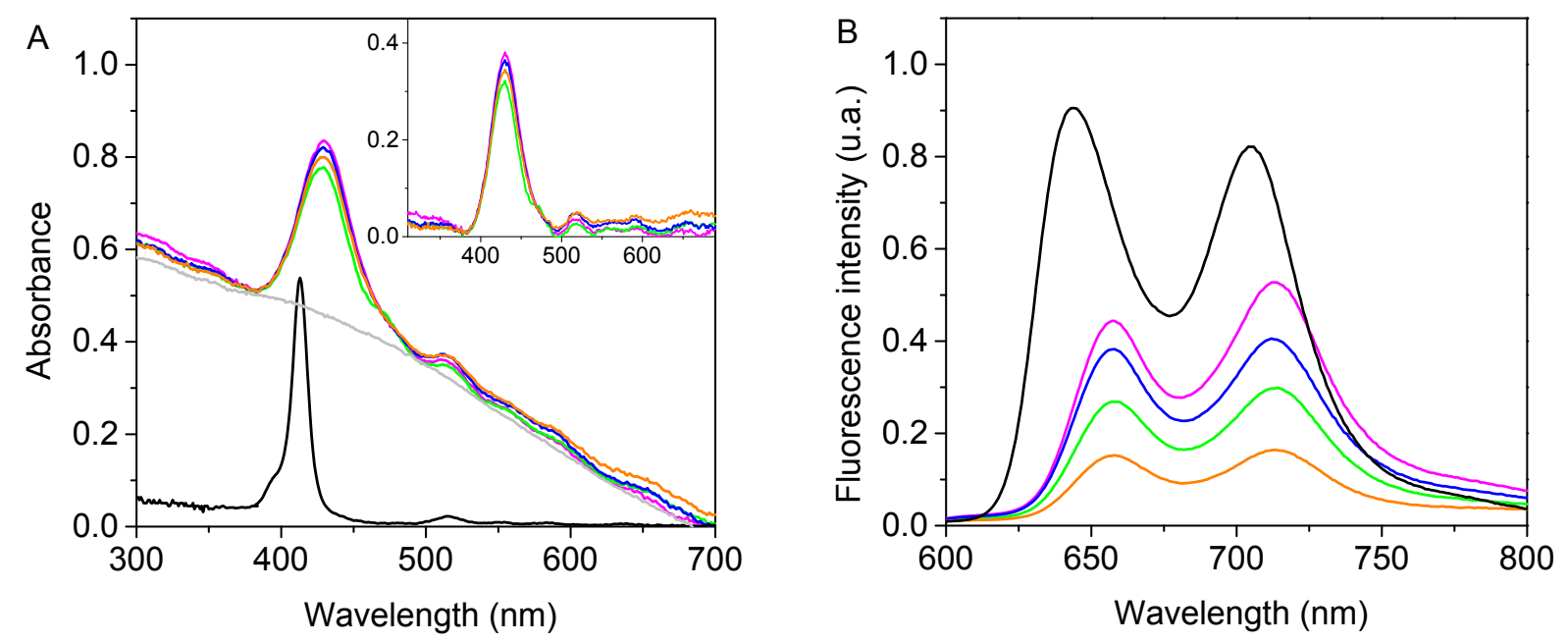

Figure 2. (A) UV-visible absorption spectra and (B) emission spectra of MNPs conjugates in water. MNP-P1 (magenta), MNP+ ${ }^{+}$P1 (green), MNP-P2 (blue), $\mathrm{MNP}^{+}-\mathrm{P} 2^{+}$(orange), $\mathrm{TPPS}^{4-}$ (black) and $\mathrm{MNPSiNH}_{2}$ scattering (gray). Inset: absorption spectra of the conjugates background corrected.

Table 1. Zeta potential $(\zeta)$ and spectroscopic properties of conjugates MNP-P1, MNP ${ }^{+}-\mathrm{P} 1, \mathrm{MNP}-\mathrm{P} 2$ and $\mathrm{MNP}^{+}-\mathrm{P}^{+}$in water.

\begin{tabular}{|c|c|c|c|c|}
\hline Conjugates & $\zeta(\mathrm{mV})^{\mathrm{a}}$ & $\lambda_{\mathrm{abs}}$ Soret $(\mathrm{nm})$ & $\lambda_{\mathrm{em}}{ }^{\max }(\mathrm{nm})$ & $\Phi_{\mathrm{F}}^{\mathrm{b}}$ \\
\hline MNP-P1 & 16 & 430 & 657 & $0.036 \pm 0.003$ \\
\hline $\mathrm{MNP}^{+}-\mathrm{P} 1$ & 19 & 430 & 657 & $0.021 \pm 0.002$ \\
\hline MNP-P2 & 27 & 430 & 657 & $0.028 \pm 0.003$ \\
\hline $\mathrm{MNP}^{+}-\mathrm{P} 2^{+}$ & 33 & 429 & 657 & $0.011 \pm 0.001$ \\
\hline
\end{tabular}




\subsection{Photosensitized oxidation of substrates}

The formation of $\mathrm{O}_{2}\left({ }^{1} \Delta_{\mathrm{g}}\right)$ sensitized by conjugates in water was detected by the decomposition of $\mathrm{ABMM}$ to form the corresponding 9,10-endoperoxide product $\mathrm{ABMM}-\mathrm{O}_{2} \cdot{ }^{27}$ Despite the short lifetime of $\mathrm{O}_{2}\left({ }^{1} \Delta_{\mathrm{g}}\right)$ in water $(\sim 4 \mu \mathrm{s}), \mathrm{ABMM}$ can act as effective trapping probe of this ROS due to its high solubility in aqueous solutions. Photooxidation of ABMM induced by conjugates was compared with that photosensitized by an anionic water-soluble porphyrin TPPS $^{4-}$. Figure $3 \mathrm{~A}$ describes the progress of the decomposition reaction for $\mathrm{ABMM}$ as first-order kinetic plots. From these plots, the values of $k_{\mathrm{obs}}{ }^{\mathrm{ABMM}}$ were calculated and they are given in Table 2. Photooxidation of ABMM was not observed in presence of $\mathrm{MNPSiN}^{+}\left(\mathrm{CH}_{3}\right)_{3}$ (Figure 3A). The photodecomposition rate of the ABMM sensitized by conjugates was about six times higher than that found for TPPS ${ }^{4-}$ in water. Moreover, highest values of $k_{\mathrm{obs}}{ }^{\mathrm{ABMM}}$ were obtained with $\mathrm{MNP}^{+}-\mathrm{P} 1$ and $\mathrm{MNP}^{+}-\mathrm{P}^{+}$, in comparison with those produced by MNP-P1 and MNP-P2. Similar results were also found when the ABMM decomposition was studied in PBS (Figure S4, Table 2). These can be attributed to the presence of four anionic groups on the malonic groups of ABMM. ${ }^{27}$ These negative charges are involved in electrostatic interactions with the positively charged of MNPs. Thus, the ABMM are located close to the side where the is sensitized by $\mathrm{TPPF}_{20}$, producing an increase in the decomposition rate of ABMM. This effect was more pronounced in conjugated with intrinsic cationic charges. In contrast, the anionic photosensitizer TPPS $^{4-}$ was repelled by the negative charges of ABMM.

To avoid this electrostatic interaction, the production of $\mathrm{O}_{2}\left({ }^{1} \Delta_{\mathrm{g}}\right)$ by the conjugates was evaluated monitoring the decomposition of DMA in DMF under aerobic condition (Figure $3 \mathrm{~B}) .{ }^{20}$ The values of $k_{\mathrm{obs}}{ }^{\mathrm{DMA}}$ were calculated from first-order kinetic plots of the DMA absorption at $378 \mathrm{~nm}$ with time. Negligible decomposition of DMA was found using $\mathrm{MNPSiN}^{+}\left(\mathrm{CH}_{3}\right)_{3}($ Figure 3B). As can be observed in Table 2, similar reaction rates were found for the conjugates, although slightly higher for MNP-P1 and $\mathrm{MNP}^{+}-\mathrm{P} 1$. However, the $k_{\mathrm{obs}}{ }^{\mathrm{DMA}}$ values sensitized by conjugates are less than half than 
that found for TPPS- in this organic solvent. Similar result was also observed for the decomposition of DMA sensitized by $\mathrm{TPPF}_{20}$. From the kinetic data of DMA decomposition, the values of $\Phi_{\Delta}$ were calculated by comparing the reaction rates for the conjugates with that for the reference (TPPS $\left.{ }^{4-}\right) .{ }^{11}$ Comparable values can be also obtained using $\mathrm{TPPF}_{20}$ as a reference $\left(\Phi_{\Delta}=0.70\right) .{ }^{38}$ The results for $\Phi_{\Delta}$ are summarized in Table 2 . On average, the $\Phi_{\Delta}$ for all the conjugates was 0.25 being the highest value for MNP-P1 (0.34) and the lowest for MNP-P2 (0.17). Values of $\Phi_{\Delta}$ of the same magnitude were previously found for porphyrin attached to MNPs. ${ }^{10}$ Comparing these values to the reference (Table 2), it can be noticed that the presence of the supermagnetic core in close proximity of the porphyrin ring affects the triplet excited state of the photosensitizer, which is responsible for producing the cytotoxic species. As described above, magnetite quenches the fluorescence emission of porphyrin units bound to MNPs possibly by PeT. ${ }^{37}$ This process can compete with the intersystem crossing producing a decrease triplet state formation and consequently $\mathrm{O}_{2}\left({ }^{1} \Delta_{\mathrm{g}}\right)$ production. ${ }^{20}$ Furthermore, the partial aggregation of the immobilized porphyrin molecules in the MNP can preclude the photodynamic activity. ${ }^{10}$ Likewise, the photodynamic activity to produce $\mathrm{O}_{2}\left({ }^{1} \Delta_{\mathrm{g}}\right)$ sensitized by conjugates was high enough to induce damage in microbial cells.
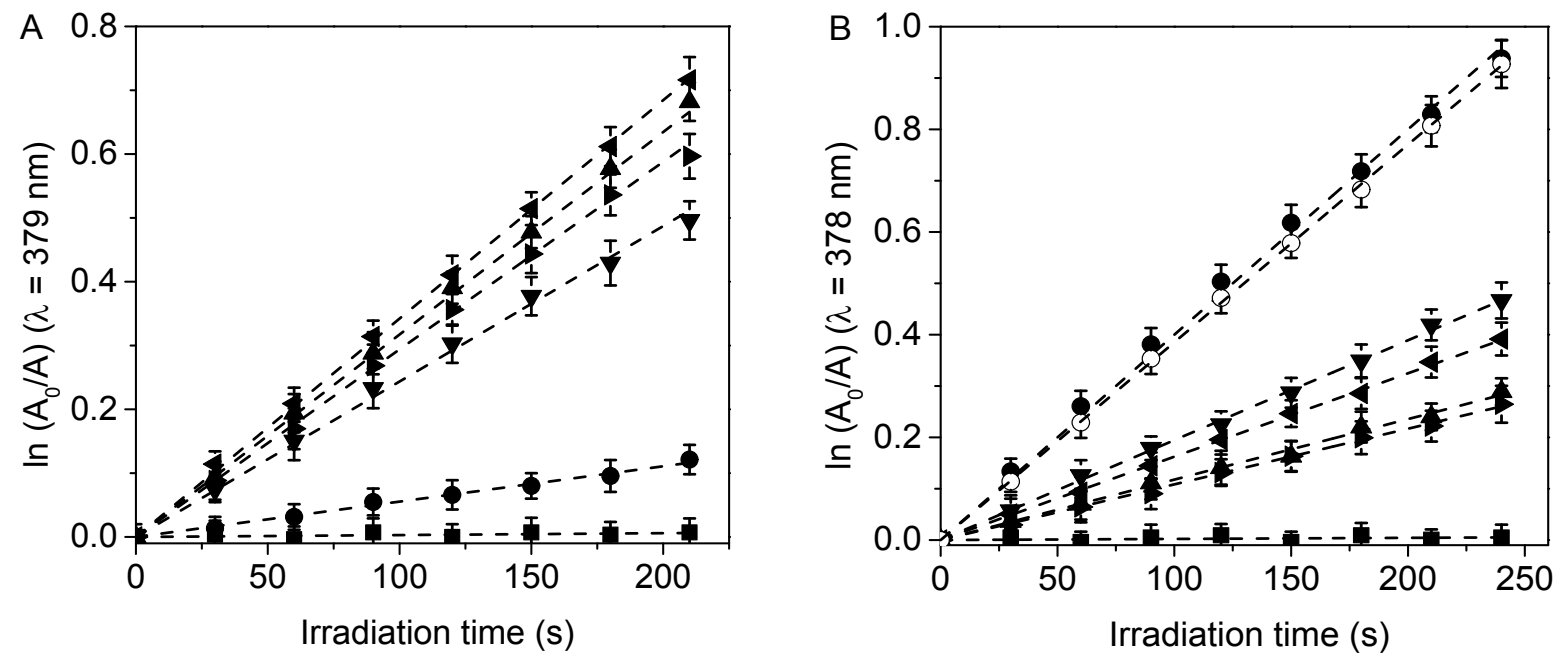
Figure 3. First-order plots for the photooxidation of (A) ABMM (35 $\mu \mathrm{M})$ in deionized water and (B) DMA $(35 \mu \mathrm{M})$ in DMF photosensitized by MNP-P1 ( $\mathbf{v}), \mathrm{MNP}^{+}-\mathrm{P} 1(\bullet), \mathrm{MNP}^{\mathrm{P}} 2(\boldsymbol{\bullet}), \mathrm{MNP}^{+}-\mathrm{P} 2^{+}(\boldsymbol{\Delta})$, $\operatorname{MNPSiN}^{+}\left(\mathrm{CH}_{3}\right)_{3}(\boldsymbol{\bullet}), \operatorname{TPPS}^{-4}(\bullet)$ and $\mathrm{TPPF}_{20}(\mathrm{o}) ; \lambda_{\text {irr }}=455-800 \mathrm{~nm}$.

Table 2. Kinetic parameters for the photooxidation reaction of ABMM $\left(k_{\mathrm{obs}}{ }^{\mathrm{ABMM}}\right)$, DMA $\left(k_{\mathrm{obs}}{ }^{\mathrm{DMA}}\right)$, $\operatorname{Trp}\left(k_{\mathrm{obs}}{ }^{\mathrm{Trp}}\right)$, and singlet molecular oxygen quantum yield $\left(\Phi_{\Delta}\right)$ sensitized by conjugates MNP-P1, $\mathrm{MNP}^{+}-\mathrm{P} 1, \mathrm{MNP}-\mathrm{P} 2$ and $\mathrm{MNP}^{+}-\mathrm{P} 2^{+}$.

\begin{tabular}{|c|c|c|c|c|}
\hline Conjugates & $k_{\mathrm{obs}}{ }^{\mathrm{ABMM}}\left(\mathrm{s}^{-1}\right)^{\mathrm{a}}$ & $k_{\mathrm{obs}}{ }^{\mathrm{ABMM}}\left(\mathrm{s}^{-1}\right)^{\mathrm{b}}$ & $k_{\mathrm{obs}}$ DMA $\left(\mathrm{s}^{-1}\right)^{\mathrm{c}}$ & $\Phi_{\Delta}^{\mathrm{d}}$ \\
\hline MNP-P1 & $(2.4 \pm 0.1) \times 10^{-3}$ & $(1.9 \pm 0.1) \times 10^{-3}$ & $(1.9 \pm 0.1) \times 10^{-3}$ & $0.34 \pm 0.02$ \\
\hline $\mathrm{MNP}^{+}-\mathrm{P} 1$ & $(3.4 \pm 0.3) \times 10^{-3}$ & $(2.9 \pm 0.2) \times 10^{-3}$ & $(1.6 \pm 0.1) \times 10^{-3}$ & $0.29 \pm 0.02$ \\
\hline MNP-P2 & $(2.9 \pm 0.2) \times 10^{-3}$ & $(1.9 \pm 0.1) \times 10^{-3}$ & $(1.0 \pm 0.1) \times 10^{-3}$ & $0.17 \pm 0.01$ \\
\hline $\mathrm{MNP}^{+}-\mathrm{P} 2^{+}$ & $(3.2 \pm 0.2) \times 10^{-3}$ & $(3.1 \pm 0.2) \times 10^{-3}$ & $(1.2 \pm 0.1) \times 10^{-3}$ & $0.21 \pm 0.01$ \\
\hline TPPS $^{4-}$ & $(5.5 \pm 0.3) \times 10^{-4}$ & $(7.8 \pm 0.4) \times 10^{-4}$ & $(4.0 \pm 0.4) \times 10^{-3}$ & 0.71 \\
\hline
\end{tabular}

\subsection{PDI in cell suspensions}

For the PDI experiments we selected two bacterial strain and a yeast with the intention of testing the conjugates in vitro in pathogenic microorganism with different cell envelopes complexities. ${ }^{7}$ Suspensions of the Gram-positive $S$. aureus, the Gram-negative E. coli and the yeast C. albicans were treated with $0.2 \mathrm{mg}$ MNPs conjugate $/ \mathrm{mL}\left(2 \mu \mathrm{M}\right.$ immobilized $\left.\mathrm{TPPF}_{20}\right)$ of the neutral and cationic conjugates. Control experiments showed that the viability of microbial cells was not affected by irradiation alone (Figure S5). Also, no toxicity was found in microorganisms treated with $0.2 \mathrm{mg} / \mathrm{mL}$ of the MNPs without porphyrin $\left(\mathrm{MNPSiNH}_{2}\right.$ and $\left.\mathrm{MNPSiN}^{+}\left(\mathrm{CH}_{3}\right)_{3}\right)$ and irradiated (Figure 4). Likewise, dark incubation with MNPs conjugates was not toxic to the cells. Therefore, 
photokilling of microbial cells observed after irradiation of the cultures incubated with the MNPs conjugates was due to the photodynamic action sensitized by porphyrin.

Cell survival for cultures treated with conjugates are shown in Figure 4. Furthermore, photokilling capacities induced by conjugates were compared with those produced by the starting porphyrin. In all cases, the inactivation of the microbial cells treated with $2 \mu \mathrm{M} \mathrm{TPPF} 20$ was less than that sensitized by the conjugates. Photoinactivation of microorganisms was dependent on irradiation times and conjugates. For all times irradiated, cell survival in the presence of the conjugates decreased significantly compared to control $(\mathrm{p}<0.05)$. The photodynamic action sensitized by $\mathrm{MNP}^{+}-\mathrm{P} 2^{+}$ produced $6 \log$ decrease in S. aureus cell survival after 30 min irradiation (Figure 4A). Similar killing activity was found for $\mathrm{MNP}^{+}-\mathrm{P} 1$ and MNP-P2 $(\mathrm{p}>0.05)$, reaching 4 log of cell inactivation, while MNP-P1 induced $3.5 \mathrm{log}$ reduction in cell viability. Also, $\mathrm{MNP}^{+}-\mathrm{P}^{+}$was effective to inactivate $S$. aureus at shorter irradiation time of $15 \mathrm{~min}$, producing $5 \mathrm{log}$ of killing. Furthermore, E. coli suspensions treated with $\mathrm{MNP}^{+}-\mathrm{P}^{+}$and irradiated for 15 min produced 2.7 log decrease in viability, whereas the photosensitizing activity of this conjugate exhibited $4.5 \log$ units after 30 min (Figure 4B). In the Gram-negative bacteria, lowest inactivating effect was also found for MNP-P1, producing a reduction of $2 \mathrm{log}$. In addition, photokilling activity induced by $\mathrm{MNP}^{+}-\mathrm{P} 1$ was slightly more effective than MNP-P2. Moreover, the photodynamic effect sensitized by the conjugates was compared in the yeast C. albicans (Figure 4C). After PDI treatment for 30 min, photoinactivation of cultures incubated with $\mathrm{MNP}^{+}-\mathrm{P}^{+}$yielded 3.7 log decrease in the cell viability. Photokilling of 2.8 $\log$ and $2.4 \log$ were found for $\mathrm{MNP}^{+}-\mathrm{P} 1$ and MNP-P2, respectively. In contrast, photocytotoxic effect mediated by MNP-P1 produced 1.9 log reduction in the survival of the yeast cells.

Comparing the inactivation in both prokaryote cells, the Gram-positive was more susceptible than the Gram-negative to the photodynamic effect induced by conjugates. This difference between the two types of bacteria can be understood by considering the structural characteristics of the cell envelope. Gram-positive bacteria have a cell wall composed of lipoteichoic and teichoic acids, which are organized in multiple layers of peptidoglycan. ${ }^{39}$ This cellular envelope gives permeability to the 
bacteria wall to facilitate the anchoring and the photodynamic action of the PSs. ${ }^{7}$ In contrast, Gramnegative bacteria have a complex outer membrane on the cell wall, which contains phospholipids, lipopolysaccharides, lipoteichoic acids, and lipoproteins, producing a protective barrier impervious to antimicrobial agents. The constituents of the Gram-negative cell wall generate electrostatic interactions with cationic PSs that promote destabilization of the native organization of the cell envelope. In the case of yeast, this eukaryotic cell contains a wall with chitin, glucans and lipoproteins that represent a barrier with intermediate permeability in comparison to Gram-positive and Gramnegative bacteria.

It is not easy to compare the PDI results obtained here with previous investigations due to the different experimental conditions used. In was demonstrated that 5,10,15-tris(1-methylpyridinium-4yl)-20-(pentafluorophenyl)porphyrin immobilized in cationized silica-coated MNPs of $\mathrm{Fe}_{3} \mathrm{O}_{4}$ was effective in the photoinactivation of both Gram-positive and Gram-negative bacteria. ${ }^{8}$ Also, the analogue with a $\mathrm{CoFe}_{2} \mathrm{O}_{4}$ core showed a notable antimicrobial activity using water contaminated with the Gram-negative bacterium Allivibrio fischeri. ${ }^{9}$ Furthermore, a cationic indium phthalocyanine attached to MNPs of $\mathrm{Fe}_{3} \mathrm{O}_{4}$ showed to be effective in the photoinactivation of E. coli. ${ }^{40}$ The $\log$ reduction produced by this material was greater than the accepted $\log 3$ and it can be easily separated with a magnet. Also, a ClIn(III) octacarboxy phthalocyanine bound to MNPs were investigated to reduce $S$. aureus cells in water samples. ${ }^{41}$ This MNPs provided $90.6 \%$ photokilling of microbes in a water sample from the stream. In the same way, a cationic indium porphyrin conjugated to $\mathrm{Ag} / \mathrm{CuFe}_{2} \mathrm{O}_{4}$ nanoparticles were able to photosensitize the inactivation of $S$. aureus. ${ }^{42}$ The quaternized porphyrin attached to $\mathrm{Ag} / \mathrm{CuFe}_{2} \mathrm{O}_{4} \mathrm{MNPs}$ produced a high reduction in the $\mathrm{S}$. aureus cell survival. A multifunctional chitosan functionalized magnetic chlorin e6 was constructed to combat $S$. aureus infection, showing an effective in vitro photodynamic sterilization ability. ${ }^{43}$ Target-oriented photofunctional nanoparticles were fabricated by an esterification reaction to introduce hematoporphyrin and $S$. aureus antibody to the surface of $\mathrm{Fe}_{3} \mathrm{O}_{4}$ nanoparticles. ${ }^{44}$ The results in vitro showed that these MNPs killed selectively S. aureus in L-929 cells and the PDI effect was also 
confirmed in vivo experiments. Moreover, a nanosystem for early sepsis diagnosis and complete extracorporeal blood disinfection was prepared based on $\mathrm{Fe}_{3} \mathrm{O}_{4}$ nanoparticles functionalized with chlorin e6 and bacterial species-identifiable aptamers. ${ }^{45}$ This nanosystem was used for successful diagnosis of sepsis caused by single $S$. aureus or multiple $S$. aureus and E. coli species of bacteria in mice. Under conditions similar to those used in the present study, PDI was investigated using 5,10,15,20-tetrakis(4-carboxyphenyl)porphyrin covalently bound to $\mathrm{MNPSiNH}_{2} \cdot{ }^{10}$ The photodynamic effect of this MNPs produced $2.5 \log$ reduction in $S$. aureus and C. albicans, while the decrease reached $3 \log$ in E. coli, after 30 min irradiation. In the present investigation, $\mathrm{MNP}^{+}-\mathrm{P}^{+}$ showed outstanding results, inactivating $99.9999 \%$ of the $S$. aureus strain in 30 min followed by $99.99 \%$ and $99.98 \%$ annihilation of $E$. coli and C. albicans, respectively. Therefore, this is an interesting photosensitizing conjugate to eradicate microorganisms.

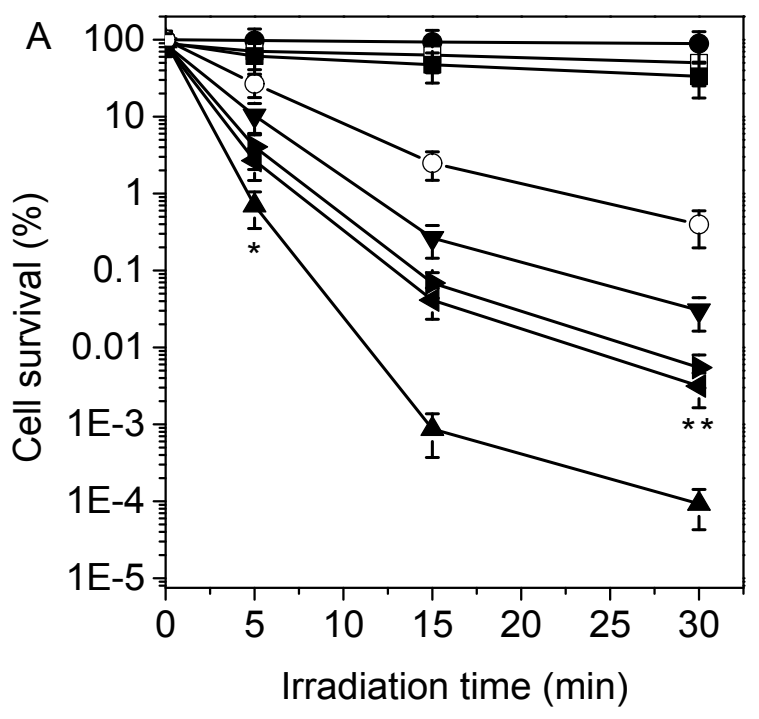



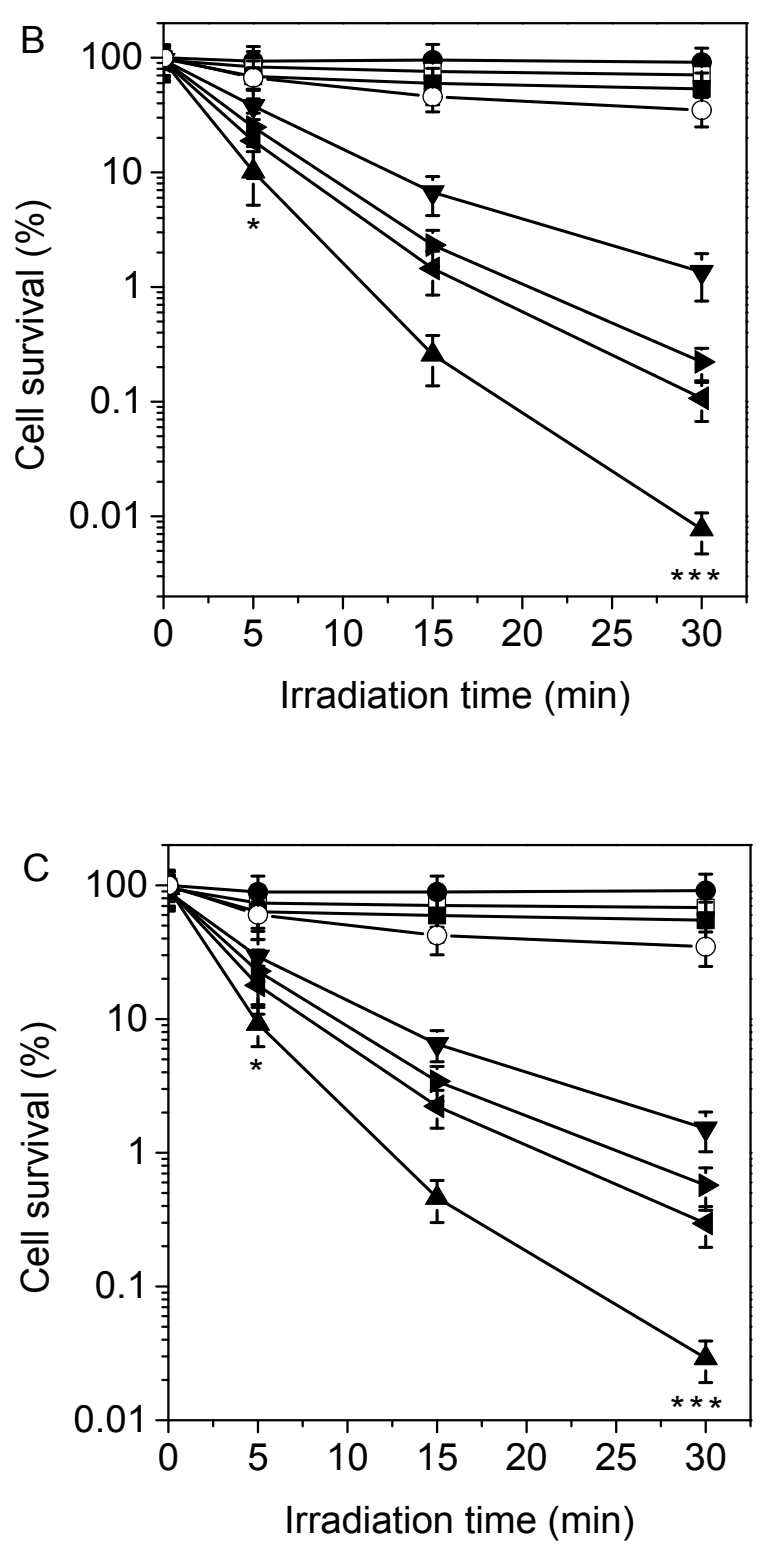

Figure 4. Cells survival of (A) S. aureus, (B) E. coli and (C) C. albicans cell suspensions treated with

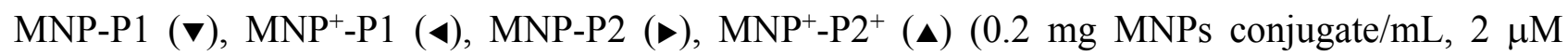
immobilized $\left.\mathrm{TPPF}_{20}\right)$ and $\mathrm{TPPF}_{20}(\mathrm{O})(2 \mu \mathrm{M})$ for $30 \mathrm{~min}$ at $37^{\circ} \mathrm{C}$ in dark and exposed to irradiation with visible light $\left(90 \mathrm{~mW} / \mathrm{cm}^{2}\right)$ for different times. Controls of untreated cells $(\bullet)$, cells incubated with $\mathrm{MNPSiNH}_{2}(\square)$ and $\mathrm{MNPSiN}^{+}\left(\mathrm{CH}_{3}\right)_{3}(\mathbf{\square})(* \mathrm{p}<0.05$ compared with control, ** $\mathrm{p}>0.05$ compared between $\mathrm{MNP}^{+}-\mathrm{P} 1$ and MNP-P2, $* * * \mathrm{p}<0.05$ compared between conjugates).

\section{6. $\mathrm{PDI}$ recycling of $\mathrm{MNP}^{+}-\mathrm{P2}^{+}$}


To test this concept, the recyclability of the $\mathrm{MNP}^{+}-\mathrm{P}^{+}{ }^{+}$was assessed in cultures treated with $\mathrm{MNP}^{+}-\mathrm{P}^{+}$. After incubation of the pathogens for $30 \mathrm{~min}$ in the dark, followed by exposition to visible light for $15 \mathrm{~min}(S$. aureus) or $30 \mathrm{~min}$ (E. coli and C. albicans) the conjugate was recovered applying magnetic decantation and reused in another PDI cycle. Cell survival results after each cycle of PDI are shown in Figure 5. After a second cycle of PDI, the photokilling of the three microorganisms incubated with $\mathrm{MNP}^{+}-\mathrm{P} 2^{+}$was the same as in the first treatment. Furthermore, photoinactivation remained effective after a third cycle of PDI, there being no significant difference between the cell survival of the three PDI experiments. In this conjugate, the silica coating avoids the oxidation of magnetite and consequent degradation of the magnetic core. It was previously found that recycling was not possible using MNPs without the silica coating protection due to structural destruction and demagnetization. ${ }^{10}$ In our case, the magnetic properties of the $\mathrm{MNP}^{+}-\mathrm{P} 2^{+}$allow the instant recovery of the conjugates after a treatment. Therefore, the PS attached to the MNPs can be reused several times. These experiments reveal that the porphyrin remains bound to the magnetic core with the same PDI potential over the cycles.

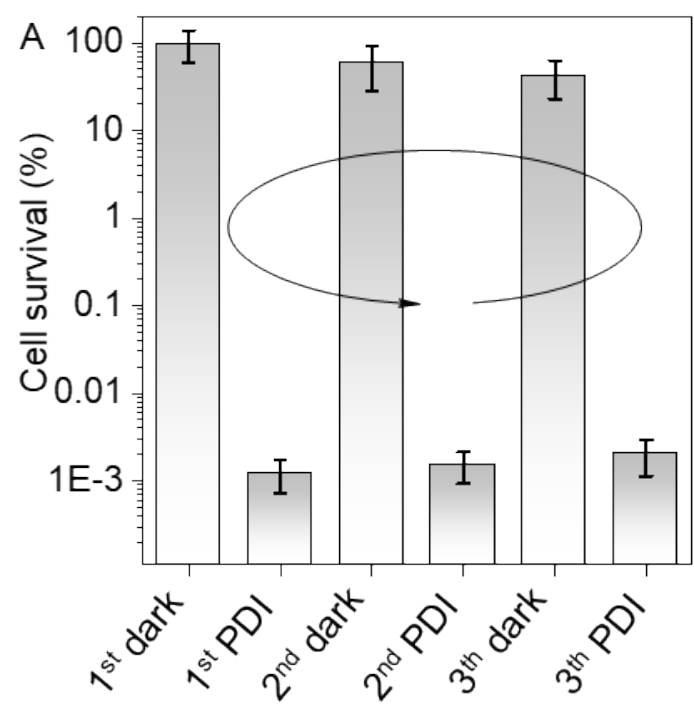



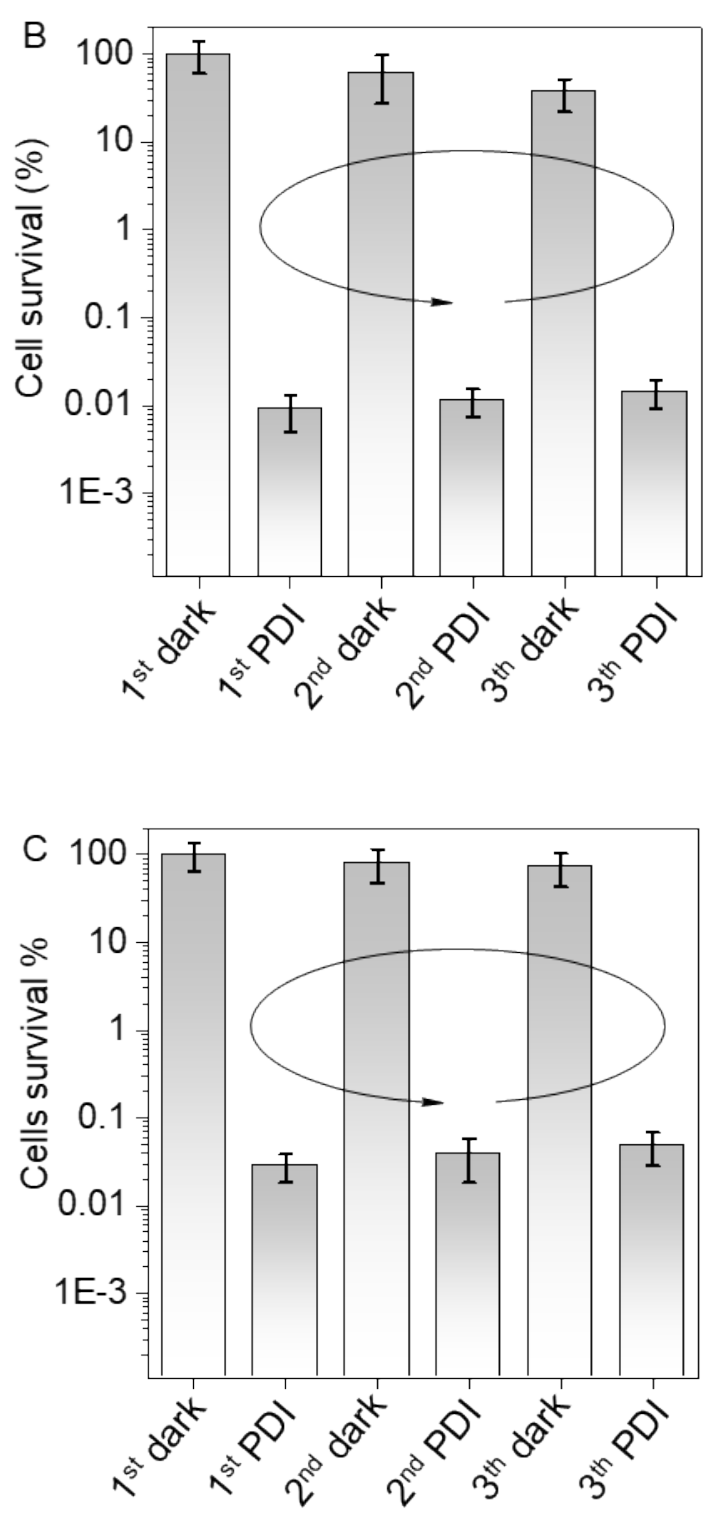

Figure 5. Cells survival of (A) S. aureus, (B) E. coli and (C) C. albicans treated with $0.2 \mathrm{mg}$ MNPs conjugate/mL ( $2 \mu \mathrm{M}$ immobilized $\left.\mathrm{TPPF}_{20}\right)$ for $30 \mathrm{~min}$ in dark and exposed to irradiation with visible light $\left(90 \mathrm{~mW} / \mathrm{cm}^{2}\right)$ for $15 \mathrm{~min}(S$. aureus $)$ and $30 \mathrm{~min}$ (E. coli and C. albicans).

\subsection{Binding and PDI of $\mathrm{MNP}^{+}-\mathrm{P2}^{+}$by fluorescence microscopy}

In the subsequent set of experiments, we examined cell binding and PDI efficacy of $\mathrm{MNP}^{+}-$ $\mathrm{P} 2^{+}$by observing bacteria under a fluorescence microscope. To focus on a determinate number of bacteria, we used a technique previously describe that involves monitoring cells attached to the surface of a coverslip in a chamber containing $200 \mu \mathrm{L}$ of PBS. ${ }^{30}$ This experimental approach relies on bacterial pilus; protrusions that assist bacterial attachment on a surface. Unfortunately, C. albicans 
lacks of these protrusions, reason why the yeast was left aside for this assay. Each fluorescence image was accompanied with a phase contrast photograph to confirm the presence and position of the bacteria. After incubation of the cells with $0.8 \mathrm{mg} \mathrm{MNP}^{+}-\mathrm{P} 2^{+}$in $200 \mathrm{~mL}$ PBS for 30 min in dark, florescence intensity reached a plateau for either $S$. aureus and E. coli, indicating complete cellular uptake of conjugate (Figure 6, first row). As can be observed, the red emission of $\mathrm{MNP}^{+}-\mathrm{P}^{+}$was detected for both bacteria, indicating the binding of this conjugate to the cells. After a previous incubation with $\mathrm{MNP}^{+}-\mathrm{P}^{+}$for 30 min in the dark, PI was added and the cells were incubated for another 15 min. PI is a well-known cell death marker that bind to DNA by intercalating between the bases upon membrane disruption. ${ }^{46}$ Unbound PI has a $\Phi_{\mathrm{F}} \sim 0.01$, similar to the value obtained for $\mathrm{MNP}^{+}-\mathrm{P} 2^{+}$in aqueous medium. Upon PI binding to DNA this emission value can increase up to 30fold. ${ }^{47}$ Since the emission spectrum of $\mathrm{MNP}^{+}-\mathrm{P} 2^{+}$and the PI overlaps, we used this difference in the values of the $\Phi_{\mathrm{F}}$ to distinguish between dead cells and living cells. Basically, the sensibility in the CMOS camera was lowered down until no fluorescence was observed after preincubation of bacteria with the PS, using a light dose of $1.2 \mathrm{~J} / \mathrm{cm}^{2}$. After $30 \mathrm{~min}$ of PDI therapy all bacteria of either strain were dead showing the enhanced red fluorescence from the cell death marker (Figure 6, middle row). Moreover, control experiments with $\mathrm{MNP}^{+}-\mathrm{P}^{2+}$ and PI incubated for $75 \mathrm{~min}$ (30 min to ensure PS uptake, $15 \mathrm{~min}$ to ensure PI uptake if cells are initially dead and another $30 \mathrm{~min}$ as control) but no irradiation showed negligible red fluorescence emission, indicating that pathogens inactivation occurs only in the presences of light (Figure 6, last row). These experiments demonstrate that the $\mathrm{MNP}^{+}-\mathrm{P}^{2+}$ conjugate was also effective in photoinactivating bacteria attached to a surface, an oversimplified example of a first stage of biofilm formation. 


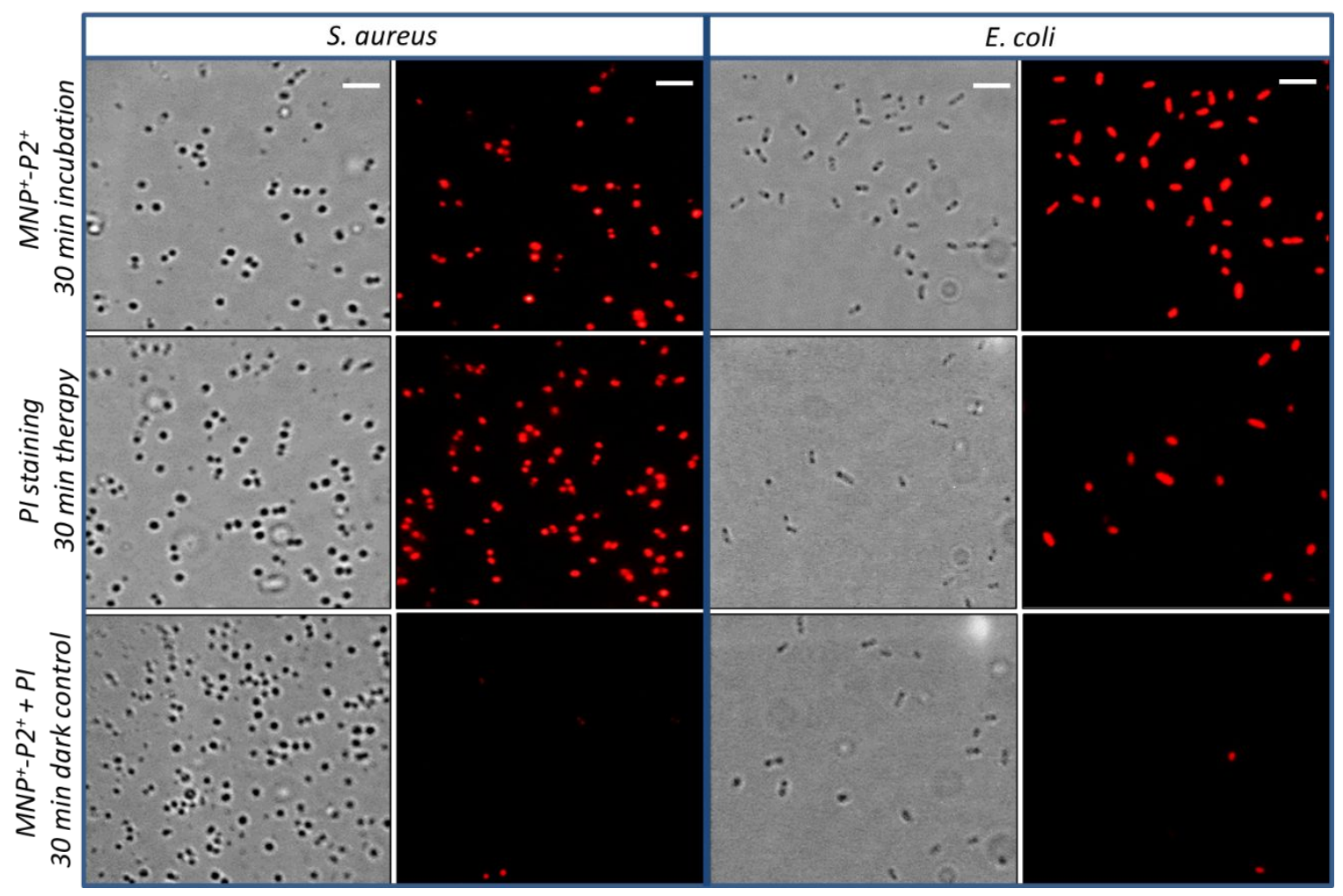

Figure 6. Microscopic images of $S$. aureus and E. coli incubated with $0.2 \mathrm{mg}$ MNPs conjugate/mL $\left(2 \mu \mathrm{M}\right.$ immobilized $\left.\mathrm{TPPF}_{20}\right)$ for $30 \mathrm{~min}$ in the dark and then irradiated with visible light for $30 \mathrm{~min}$. First and third columns, cells under bright field; second and fourth columns, fluorescence emission fluorescence emission of PI after the PDI treatment (scale bar $5 \mu \mathrm{m}$ ).

\section{CONCLUSIONS}

In this work, the MNP-P1 conjugate was synthesized by covalently binding $\mathrm{TPPF}_{20}$ to MNPSiNH2 through the $\mathrm{S}_{\mathrm{N}} \mathrm{Ar}$ reaction of the $\mathrm{F}$ atom in the para position of the pentafluorophenyl groups of the porphyrin. This conjugate was the platform to obtain modifications in the tetrapyrrolic macrocycle. Thus, it was possible to add dimethylaminoethoxy groups to the $\mathrm{TPPF}_{20}$ porphyrin immobilized on the MNPs. This synthetic modification also involves the $\mathrm{S}_{\mathrm{N}} \mathrm{Ar}$ reaction of the $\mathrm{F}$ atoms in the para-remaining positions to produce MNP-P2. The periphery of this conjugate is crowded with basic aliphatic amine groups, which can acquire positive charges in aqueous media by protonation.

Furthermore, the amine substituents in MNP-P1 and MNP-P2 were methylated to form conjugates with intrinsic cationic charges named $\mathrm{MNP}^{+}-\mathrm{P} 1$ and $\mathrm{MNP}^{+}-\mathrm{P} 2^{+}$, respectively. An average size of 12 
$\pm 2 \mathrm{~nm}$ was found for these MNPs, while the main difference between conjugates was the greater coating with positive charges of $\mathrm{MNP}^{+}-\mathrm{P}^{+}$, as indicated by the $\zeta$ values. This approach of in situ modification and purification by magnetic decantation allows to obtain conjugates with a simple procedure and high yields. The UV-visible spectra of each conjugate showed the characteristic bands of the porphyrin that correspond to $\mathrm{TPPF}_{20}$ immobilized in the MNPs. In all cases, a bathochromic shift of the Soret band was found with respect to it of free $\mathrm{TPPF}_{20}$. Furthermore, the porphyrin bound to the MNPs retain the ability to emit red fluorescence. These spectroscopic results corroborated the binding between porphyrin and MNPs. On the other hand, the photodecomposition of oxidizable substrates in the presence of the different conjugates indicated an efficient production of $\mathrm{O}_{2}\left({ }^{1} \Delta_{\mathrm{g}}\right)$. PDI studies in $S$. aureus, E. coli and C. albicans indicate that $\mathrm{MNP}^{+}-\mathrm{P} 2^{+}$is the most effective conjugate for the eradication of microorganisms. In contrast, the lowest photoinactivating capacity was found for the unmodified MNP-P1 conjugate. Microscopic observations indicated the binding of $\mathrm{MNP}^{+}-\mathrm{P}^{+}$ to cells and its ability to photoinactivate individual cells of bacteria attached to a surface. Moreover, this conjugate can be recycled and reused, reducing the costs of PDI applications and without contaminating the environment. Thus, in situ approach is a suitable scaffold to obtain modified conjugates and the intrinsically charged $\mathrm{MNP}^{+}-\mathrm{P}^{+}$is an interesting photoactive material to inactivate pathogens.

\author{
ASSOCIATED CONTENT \\ Supporting Information \\ The Supporting Information is available free of charge at https://pubs.acs.org/doi/. \\ Materials, instrumentation, methodology for the synthesis of conjugates, TEM images of conjugates, \\ UV-visible absorption spectra of MNPs conjugates in DMF, First-order plots for the photooxidation \\ of ABMM in PBS and cells survival controls of microorganisms (PDF).
}

\title{
AUTHOR INFORMATION
}




\section{Corresponding Author}

Edgardo N. Durantini - Universidad Nacional de Río Cuarto, Río Cuarto, Argentina; orcid.org/00000001-8901-7543; Phone: +54 358 4676157; E-mail: edurantini@exa.unrc.edu; Fax: +54 3584676233

Other Authors

Ana C. Scanone - Universidad Nacional de Río Cuarto, Río Cuarto, Argentina; orcid.org/0000-0001$6306-216 \mathrm{X}$

Natalia S. Gsponer - Universidad Nacional de Río Cuarto, Río Cuarto, Argentina; orcid.org/00000003-3012-7590

María G. Alvarez - Universidad Nacional de Río Cuarto, Río Cuarto, Argentina; orcid.org/00000002-1051-3390

Daniel A. Heredia - Universidad Nacional de Río Cuarto, Río Cuarto, Argentina; orcid.org/ 00000002-0667-3906

Andrés M. Durantini - Universidad Nacional de Río Cuarto, Río Cuarto, Argentina; orcid.org/ 00000002-7898-4033

\section{Notes}

The authors declare no competing financial interest.

\section{ACKNOWLEDGEMENTS}

Authors are grateful to ANPCYT (PICT-2016 0667), MINCyT Córdoba (PID-2018 36) and SECYT-UNRC (PPI-2020) for financial support. N.S.G, M.G.A., A.M.D, E.N.D. are Scientific Members of CONICET. A.C.S. thanks CONICET for a research fellowship.

\section{REFERENCES}


(1) Laurent, S.; Forge, D.; Port, M.; Roch, A.; Robic, C.; Elst, L. V.; Muller, R. N. Magnetic iron oxide nanoparticles: synthesis, stabilization, vectorization, physicochemical characterizations, and biological applications. Chem. Rev. 2008, 108, 2064-2110.

(2) Bañobre-López, M.; Teijeiro, A.; Rivas, J. Magnetic nanoparticle-based hyperthermia for cancer treatment. Rep. Pract. Oncol. Radiother. 2013, 18, 397-400.

(3) Li, Y.; Wang, N.; Huang, X.; Li, F.; Davis, T. P.; Qiao, R.; Ling, D. Polymer-assisted magnetic nanoparticle assemblies for biomedical applications, ACS Appl. Bio Mater. 2020, 3, 121-142.

(4) Zhou, K.; Zhou, X.; Liu, J.; Huang, Z. Application of magnetic nanoparticles in petroleum industry: a review. J. Petrol. Sci. Eng. 2020, 188, 106943.

(5) Mesquita, M. Q.; Dias, C. J.; Neves, M. G. P. M. S.; Almeida, A.; Faustino, M. A. F. Revisiting current photoactive materials for antimicrobial photodynamic therapy. Molecules 2018, 23, 2424.

(6) Feng, Y.; Liu, L.; Zhang, J.; Aslan, H.; Dong, M. Photoactive antimicrobial nanomaterials. J. Mater. Chem. B 2017, 5, 8631-8652.

(7) Durantini, A. M.; Heredia, D. A.; Durantini, J. E.; Durantini, E. N. BODIPYs to the rescue: potential applications in photodynamic inactivation. Eur. J. Med. Chem. 2018, 144, 651-661.

(8) Carvalho, C. M. B.; Alves, E.; Costa, L.; Tomé, J. P. C.; Faustino, M. A. F.; Neves, M. G. P. M. S.; Tomé, A. C.; Cavaleiro, J. A. S.; Almeida, A.; Cunha, A.; Lin, Z.; Rocha, J. Functional cationic nanomagnet-porphyrin hybrids for the photoinactivation of microorganisms. ACS Nano 2010, 4, 7133-7140.

(9) Alves, E.; Rodrigues, J. M. M.; Faustino, M. A. F.; Neves, M. G. P. M. S.; Cavaleiro, J. A. S.; Lin, Z.; Cunha, Â.; Nadais, M. H.; Tomé, J. P. C.; Almeida, A. A new insight on nanomagneteporphyrin hybrids for photodynamic inactivation of microorganisms. Dyes Pigm. 2014, $110,80-88$

(10) Scanone, A. C.; Gsponer, N. S.; Alvarez, M. G.; Durantini, E. N. Photodynamic properties and photoinactivation of microorganisms mediated by 5,10,15,20-tetrakis(4- 
carboxyphenyl)porphyrin covalently linked to silica-coated magnetite nanoparticles. J. Photochem. Photobiol. A: Chem. 2017, 346, 452-461.

(11) Scanone, A. C.; Gsponer, N. S.; Alvarez, M. G.; Durantini, E. N. Porphyrins containing basic aliphatic amino groups as potential broad-spectrum antimicrobial agents. Photodiagn. Photodyn. Ther. 2018, 24, 220-227.

(12) Durantini, E. N.; Silber, J. J. Synthesis of 5-(4-acetamidophenyl)-10,15,20-tris(4-substituted phenyl) porphyrins using dipyrromethanes. Synth. Commun. 1999, 29, 3353-3368.

(13) Ballatore, M. B.; Spesia, M. B.; Milanesio, M. E.; Durantini, E. N. Synthesis, spectroscopic properties and photodynamic activity of porphyrin-fullerene $\mathrm{C}_{60}$ dyads with application in the photodynamic inactivation of Staphylococcus aureus. Eur. J. Med. Chem. 2014, 83, 685-694.

(14) Dommaschk, M.; Gutzeit, F.; Boretius, S.; Haag, R.; Herges, R. Coordination-induced spinstate-switch (CISSS) in water. Chem. Commun. 2014, 50, 12476-12478.

(15) Heredia, D. A.; Martínez, S. R.; Durantini, A. M.; Pérez, M. E.; Mangione, M. I.; Durantini, J. E.; Gervaldo, M. A.; Otero, L. A.; Durantini, E. N. Antimicrobial photodynamic polymeric films bearing biscarbazol triphenylamine end-capped dendrimeric $\mathrm{Zn}(\mathrm{II})$ porphyrin. ACS Appl. Mater. Interfaces 2019, 11, 27574-27587.

(16) Bhupathiraju, N. V. S. D. K.; Rizvi, W.; Batteas, J. D.; Drain, C. M. Fluorinated porphyrinoids as efficient platforms for new photonic materials, sensors, and therapeutics. Org. Biomol. Chem. 2016, 14, 389-408.

(17) Olofsson, M.; Matussek, A.; Ehricht, R.; Lindgren, P. E.; Östgren, C. J. Differences in molecular epidemiology of Staphylococcus aureus and Escherichia coli in nursing home residents and people in unassisted living situations. J. Hosp. Infect. 2019, 101, 76-83.

(18) Singh, R.; Singh, A. P.; Kumar, S.; Giri, B. S.; Kim, K. H. Antibiotic resistance in major rivers in the world: a systematic review on occurrence, emergence, and management strategies. $J$. Clean. Prod. 2019, 234, 1484-1505. 
(19) Janbon, G.; Quintin, J.; Lanternier, F.; d'Enfert, C. Studying fungal pathogens of humans and fungal infections: fungal diversity and diversity of approaches. Microb. Infect. 2019, 21, 6237-6245.

(20) Scanone, A. C.; Santamarina, S. C.; Heredia, D. A.; Durantini, E. N.; Durantini, A. M. Functionalized magnetic nanoparticles with BODIPYs for bioimaging and antimicrobial therapy applications. ACS Appl. Bio Mater. 2020, 3, 1061-1070.

(21) McClure, J. E.; Baudouin, L.; Mansuy, D.; Marzilli, L. G. Interactions of DNA with a new electron-deficient tentacle porphyrin: meso-tetrakis[2,3,5,6-tetrafluoro-4-(2-trimethylammoniumethylamine)phenyl]porphyrin. Biopolymers 1997, 42, 203-217.

(22) Gutsche, C. S.; Ortwerth, M.; Gräfe, S.; Flanagan, K. J.; Senge, M. O.; Reissig, H. U.; Kulak, N.; Wiehe, A. Nucleophilic aromatic substitution on pentafluorophenyl-substituted dipyrranes and tetrapyrroles as a route to multifunctionalized chromophores for potential application in photodynamic therapy. Chem. Eur. J. 2016, 22, 13953-13964.

(23) Golf, H. R. A.; Reissig, H-U.; Wiehe, A. Regioselective nucleophilic aromatic substitution reaction of meso-pentafluorophenyl-substituted porphyrinoids with alcohols. Eur. J. Org. Chem. 2015, 7, 1548-1568.

(24) Vasti, C.; Giacomelli, C. E.; Rojas, R. Pros and cons of coating layered double hydroxide nanoparticles with polyacrylate. Appl. Clay Sci. 2019, 172, 11-18.

(25) Kalyanasundaram, K.; Neumann-Spallart, M. Photophysical and redox properties of watersoluble porphyrins in aqueous media. J. Phys. Chem. 1982, 86, 5163-5169.

(26) Gottfried V., P. D., Winkelman J.W., Kimel S. Photosensitizers in organized media: singlet oxygen production and spectral properties. Photochem. Photobiol. 1988, 48, 157-163.

(27) Mora, S. J.; Milanesio, M. E.; Durantini, E. N. Spectroscopic and photodynamic properties of 5,10,15,20-tetrakis[4-(3-N,N-dimethylaminopropoxy)phenyl]porphyrin and its tetracationic derivative in different media. J. Photochem. Photobiol. A: Chem. 2013, 270, 75-84. 
(28) Ferreyra, D. D.; Reynoso, E.; Cordero, P.; Spesia, M. B.; Alvarez, M. G.; Milanesio, M. E.; Durantini, E. N. Synthesis and properties of 5,10,15,20-tetrakis[4-(3- $N, N$ dimethylaminopropoxy)phenyl] chlorin as potential broad-spectrum antimicrobial photosensitizers. J. Photochem. Photobiol. B: Biol. 2016, 158, 243-251.

(29) Ballatore, M. B.; Milanesio, M. E.; Fujita, H.; Lindsey, J. S.; Durantini, E. N. Bacteriochlorinbis(spermine) conjugate affords an effective photodynamic action to eradicate microorganisms. $J$. Biophotonics 2020, 13, e201960061.

(30) Martínez, S. R.; Palacios, Y. B.; Heredia, D. A.; Agazzi, M. L.; Durantini, A. M. Phenotypic resistance in photodynamic inactivation unravelled at the single bacterium level. ACS Infect. Dis. 2019, 5, 1624-1633.

(31) Vives, G.; Giansante, C.; Bofinger, R.; Raffy, G.; Del Guerzo, A.; Kauffmann, B.; Batat, P.; Jonusauskas, G.; McClenaghan, N. D. Facile functionalization of a fully fluorescent perfluorophenyl BODIPY: photostable thiol and amine conjugates. Chem. Commun. 2011, 47, 10425-10427.

(32) Quiroga, E. D.; Mora, S. J.; Alvarez, M. G.; Durantini, E. N. Photodynamic inactivation of Candida albicans by a tetracationic tentacle porphyrin and its analogue without intrinsic charges in presence of fluconazole. Photodiag. Photodyn. Ther. 2016, 13, 334-340.

(33) El-Shabouri, M.H. Positively charged nanoparticles for improving the oral bioavailability of cyclosporin-A. Int. J. Pharm. 2002, 249, 101-108.

(34) Reddy, P. M.; Chang, K. C.; Liu, Z. J.; Chen, C. T.; Ho, Y. P. Functionalized magnetic iron oxide $\left(\mathrm{Fe}_{3} \mathrm{O}_{4}\right)$ nanoparticles for capturing Gram-positive and Gram-negative bacteria. J. Biomed. Nanotech. 2014, 10, 1429-1439.

(35) Penon, O.; Marín, M. J.; Amabilino, D. B.; Russell, D. A.; Pérez-García, L. Iron oxide nanoparticles functionalized with novel hydrophobic and hydrophilic porphyrins as potential agents for photodynamic therapy. J. Colloid Interface Sci. 2016, 462, 154-165.

(36) Heredia, D. A.; Durantini, A. M.; Sarotti, A. M.; Gsponer, N. S.; Ferreyra, D. D.; Bertolotti, S. G.; Milanesio, M. E.; Durantini, E. N. Proton-dependent switching of a novel amino chlorin 
derivative as a fluorescent probe and photosensitizer for acidic media. Chem. Eur. J. 2018, 24, 59505961.

(37) Yu, C. J.; Wu, S. M.; Tseng, W. L. Magnetite nanoparticle-induced fluorescence quenching of adenosine triphosphate-BODIPY conjugates: application to adenosine triphosphate and pyrophosphate sensing. Anal. Chem. 2013, 85, 8559-8565.

(38) Grancho, J. C. P.; Pereira, M. M.; Miguel, M. da G.; Rocha Gonsalves, A. M.; Burrows, H. D. Synthesis, spectra and photophysics of some free base tetrafluoroalkyl and tetrafluoroaryl porphyrins with potential applications in imaging. Photochem. Photobiol. 2002, 75, 249-256.

(39) Malanovic, N.; Lohner, K. Gram-positive bacterial cell envelopes: the impact on the activity of antimicrobial peptides. Biochim. Biophys. Acta-Biomembranes 2016, 1858, 936-946.

(40) Osifeko, O. L.; Uddin, I.; Mashazi, P. N.; Nyokong, T. Physicochemical and antimicrobial photodynamic chemotherapy of unsymmetrical indium phthalocyanines alone or in the presence of magnetic nanoparticles. New J. Chem. 2016, 40, 2710-2721.

(41) Sindelo, A.; Nyokong, T. Magnetic nanoparticle-indium phthalocyanine conjugate embedded in electrospun fiber for photodynamic antimicrobial chemotherapy and photodegradation of methyl red. Heliyon 2019, 5, e02352.

(42) Makola, L. C.; Managa, M.; Nyokong, T. Enhancement of photodynamic antimicrobial therapy through the use of cationic indium porphyrin conjugated to $\mathrm{Ag} / \mathrm{CuFe}_{2} \mathrm{O}_{4}$ nanoparticles.

Photodiagn. Photodyn. Ther. 2020, 30, 101736.

(43) Lu, C.; Sun, F.; Liu, Y.; Xiao, Y.; Qiu, Y.; Mu, H.; Duan, J. Versatile Chlorin e6-based magnetic polydopamine nanoparticles for effectively capturing and killing MRSA. Carbohydr. Polym. 2019, 218, 289-298.

(44) Wang, K. K.; Shin, E. P.; Lee, H. J.; Jung, S. J.; Hwang, J. W.; Heo, I.; Kim, J. H.; Oh, M. K.; Kim Y. R. Target-oriented photofunctional nanoparticles (TOPFNs) for selective photodynamic inactivation of methicillin-resistant Staphylococcus aureus (MRSA). J. Photochem. Photobiol. B: Biol. 2018, 183, 184-190. 
(45) Wang, J.; Wu, H.; Yang, Y.; Yan, R.; Zhao, Y.; Wang, Y.; Chen, A.; Shao, S.; Jiang, P.; Li, Y. Q. Bacterial species-identifiable magnetic nanosystems for early sepsis diagnosis and extracorporeal photodynamic blood disinfection. Nanoscale 2018, 10, 132-141.

(46) Duedu, K. O.; French, C. E. Two-colour fluorescence fluorimetric analysis for direct quantification of bacteria and its application in monitoring bacterial growth in cellulose degradation systems. J. Microbiol. Methods 2017, 135, 85-92.

(47) Samanta, A.; Paul, B. K.; Guchhait, N.; Photophysics of DNA staining dye propidium iodide encapsulated in bio-mimetic micelle and genomic fish sperm DNA. J. Photochem. Photobiol. B: Biol. 2012, 109, 58-67. 


\section{MNPs in situ modifications}

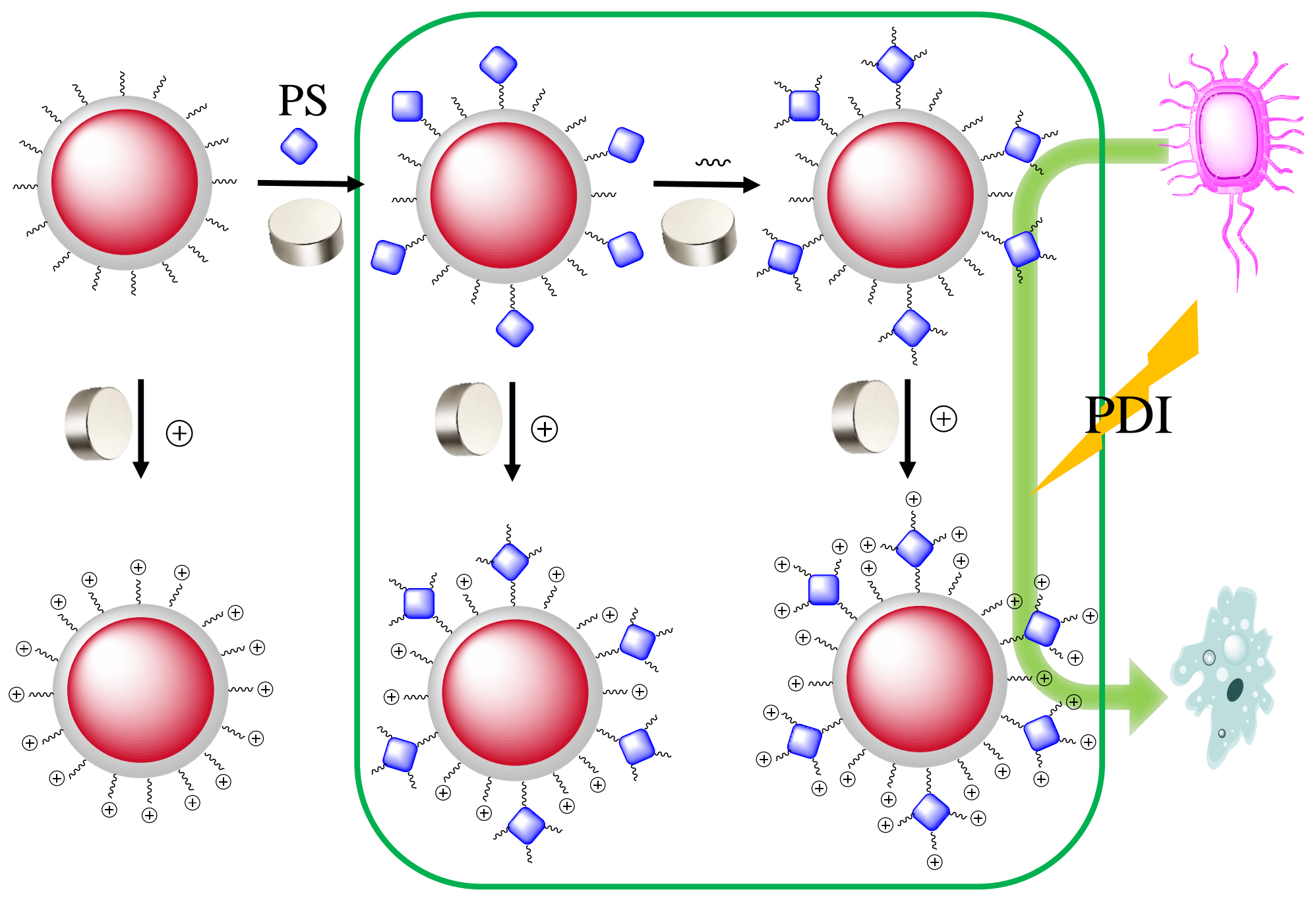

